\title{
Computer-Assisted Instruction Compared to Traditional Instruction on Letter Recognition for Preschoolers with Special Needs
}

Jamie Nicole Harvey

jnh0001@mix.wvu.edu

Follow this and additional works at: https://researchrepository.wvu.edu/etd

Part of the Early Childhood Education Commons, and the Special Education and Teaching Commons

\section{Recommended Citation}

Harvey, Jamie Nicole, "Computer-Assisted Instruction Compared to Traditional Instruction on Letter Recognition for Preschoolers with Special Needs" (2019). Graduate Theses, Dissertations, and Problem Reports. 4032.

https://researchrepository.wvu.edu/etd/4032

This Dissertation is protected by copyright and/or related rights. It has been brought to you by the The Research Repository @ WVU with permission from the rights-holder(s). You are free to use this Dissertation in any way that is permitted by the copyright and related rights legislation that applies to your use. For other uses you must obtain permission from the rights-holder(s) directly, unless additional rights are indicated by a Creative Commons license in the record and/ or on the work itself. This Dissertation has been accepted for inclusion in WVU Graduate Theses, Dissertations, and Problem Reports collection by an authorized administrator of The Research Repository @ WVU.

For more information, please contact researchrepository@mail.wvu.edu. 
Computer-Assisted Instruction Compared to Traditional Instruction on Letter Recognition for Preschoolers with Special Needs

\author{
Jamie N. Harvey \\ Dissertation submitted to the College of Education and Human Services \\ at West Virginia University \\ in partial fulfillment of the requirements for the degree of \\ Doctor of Education in Special Education - Personnel Preparation \\ Kimberly Floyd, Ph.D., Chair \\ Alexandra Hollo, Ph.D., BCBA-D \\ Colleen Wood-Fields, Ph.D. \\ Amy Root, Ph.D. \\ Department of Special Education \\ Department of Learning Sciences and Human Development
}

Morgantown, West Virginia 2019

Keywords: computer assisted instruction, early literacy, early childhood special education, inclusive, preschool, letter recognition

Copyright 2019 Jamie N. Harvey 


\begin{abstract}
Computer-Assisted Instruction Compared to Traditional Instruction on Letter Recognition for Preschoolers with Special Needs
\end{abstract}

\title{
Jamie N. Harvey
}

The need to reach learners with disabilities in inclusive early childhood classrooms has grown with increasing legislative mandates. An essential area of focus is in early literacy and alphabet letter recognition. One such way to bridge the gap includes computer assisted instruction as an instructional method. A concurrent treatment single case design was used to compare the rate of letter acquisition in young children with disabilities $(n=6)$ between computer assisted instruction program, Teach Town Basics ${ }^{\mathrm{TM}}$, and traditional teaching of concepts in early childhood inclusive classrooms. Participants received each treatment in random order and data were graphed daily on the same graph. The findings suggest that students learned letters at a greater rate using the Teach Town Basics ${ }^{\mathrm{TM}}$ compared to the traditional teaching. The majority of the students made gains in acquiring letter knowledge, as evidenced by the data collected and the PALS reports. The study advances research for the use of iPads for teaching early literacy concepts of young children with disabilities in inclusive settings. 


\section{Table of Contents}

Page

List of Tables.........................................................

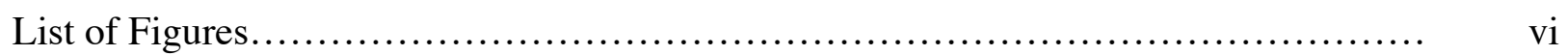

Introduction. ............................................................ 1

Literature Review........................................................ 2

Method..................................................................... 10

Participants..................................................... 13

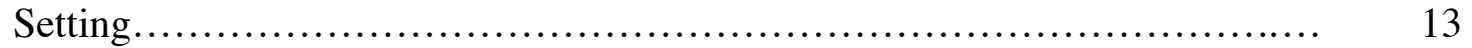

Variables....................................................... 14

Procedures......................................................... 16

Baseline.............................................................. 18

Interventions ......................................................... 18

Maintenance.................................................... 20

Data Analysis Plan................................................. 22

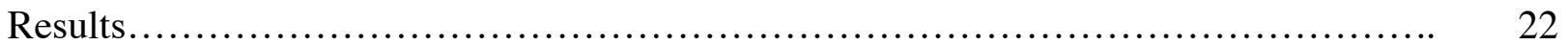

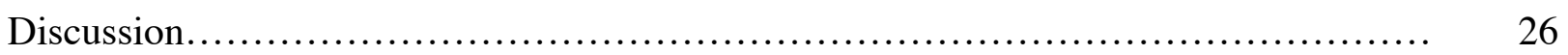

Limitations.................................................... 28

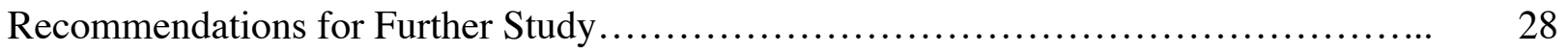

Conclusion............................................................. 29

References............................................................. 30

Tables................................................................... 35

Figures............................................................. 40

Appendices................................................................ 44

Appendix A....................................................... 44

Appendix B..................................................... 45

Appendix C....................................................... 50

Appendix D.................................................... 54 
Appendix E....................................................... 55

Appendix F....................................................... 56

Appendix G.................................................... 57

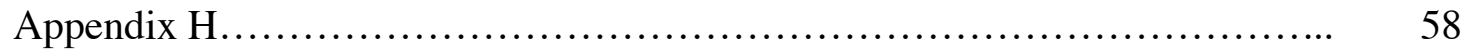

Appendix I...................................................... 59

Appendix J.................................................... 60 


\section{List of Tables}

Table

Page

Characteristics of Participants.

2 Letters Identified Per Session for

Cameron...............................

Hannah.

Kylie

5 Letters Identified Per Session for

Katie.

6 Letters Identified Per Session for

Serenity....

7 Letters Identified Per Session for Sara.

8 Phonological Awareness and Literacy Screening (PALS) Results for 


\section{List of Figures}

Figure

Page

$1 \quad$ Mean Average of Responses for Cameron........................... 40

2 Mean Average of Responses for Hannah........................... 41

$3 \quad$ Mean Average of Responses for Kylie............................. 41

$4 \quad$ Mean Average of Responses for Katie.............................. 42

$5 \quad$ Mean Average of Responses for Serenity.......................... 42

$6 \quad$ Mean Average of Responses for Sara................................. 43 


\section{Computer-Assisted Instruction Compared to Traditional Instruction on Letter Recognition for Preschoolers with Special Needs}

The 2009 NAEYC position statement on developmentally appropriate practice identifies a gap with regards to early learning and mandated standards in the area of early literacy (NAEYC, 2009). Early literacy refers to multiple skills including phonemic awareness, print knowledge, and alphabet knowledge (Invernizzi, Sullivan, Meier, \& Swank, 2004). Two important skills in the development of early literacy is alphabet letter knowledge recognition and acquisition. Both skills are key in the development of later reading achievement and for all students (Invernizzi, et al., 2004). Students with disabilities face a significant challenge in this area due to language impairments and speech language impairments that impact readiness to read as early as four to five years of age (Justice et al., 2015). Failure in developing early literacy skills then leads to long terms problems in reading (Chai, Vail, \& Ayres, 2015).

Current research indicates that traditional preschool instruction in early literacy may not be adequate for teaching young children with disabilities or those who are at-risk for disabilities (Goldstein et al., 2017). In addition, professional development for early childhood educators does not provide professionals with the tools and skills needed to meet the unique needs of learners with disabilities (Odom, Buysse, \& Soukakou, 2011). One way to vary the type of instruction in early childhood settings is to infuse of technology to enhance learning. The use of technology in education has become a widely accepted practice across all areas of instruction and all ages of students (Herold, 2016). Computer-assisted instruction (CAI) is one such use of technology that incorporates computers, tablets, and other digital interfaces to influence learning of academic skills (National Professional Development Center on Autism Spectrum Disorder, 
2015). CAI has been shown to be effective for the acquisition of new skills for individuals with disabilities, including skills within literacy and language development.

Thus, the purpose of this study was to examine one aspect of early literacy development and compare traditional early childhood teaching methods to CAI based activities. After discussing of key components of traditional and computer-assisted instruction, I will detail the methods and procedures of a study examining the efficacy of CAI in early childhood settings for children with special needs and letter identification. Next, I will present the results, followed by a discussion of findings, limitations, and implications for practice. I will conclude with potential for future research.

\section{Importance of Early Literacy Skills}

A recent trend in the United States is the shift towards universal Pre-K programming for all 4-year olds which has increased the importance of overall academics in early childhood education (Invernizzi, Landrum, Teichman, \& Townsend, 2010). With this increased importance comes a new emphasis on screening and assessments targeting needed areas, including early literacy. Early childhood teachers are expected to expand and create more opportunities for intensive instruction and rigor for their classrooms while keeping developmentally appropriate practice in mind (NAEYC, 2009). Through early childhood assessments and screenings, early childhood educators can target areas for growth and implement change needed for success within their classrooms (Invernizzi, et al., 2010).

Early literacy development for young children with disabilities is an area of concern when related to future reading achievement (Justice et al., 2015). Children with delays in language development or speech and language development demonstrated evidence linking them to difficulties in reading readiness and potential for future reading disability. Additionally, 
children with significant delays early literacy specifically demonstrated deficits in phonological awareness and alphabet knowledge (Goldstein et al., 2017). Among the skills targeted, phonological awareness, print awareness, and alphabet knowledge were identified as being the most important for these students. Preschool curricula were used to address these deficits was not adequate enough to teach early literacy skills in a manner to support those students with significant needs. However, when additional supports and specified instruction were presented, children demonstrated higher scores on early literacy assessments (Goldstein et al., 2017).

By supporting young learners with disabilities with supplemental instruction in early literacy, the possibility of reducing the risk of future challenges in reading achievement increases. With the use and availability of technology in early childhood classrooms, especially tablets, early literacy skills can be differentiated to meet the needs of young children with disabilities (Beschorner \& Hutchison, 2013). Tablets allow for young learners to touch to select and explore options through a different format from traditionally presented materials. Additionally, early learning apps and instructional software provide repeated practice and often support immediate feedback. For students with motor delays, the ease of accessibility is vital. This interactive interface also allows for developmentally appropriate practice, creativity, exploration, choice, and play, to remain in place (Dietze \& Kashin, 2013). Limited research is available on the use of tablets in early childhood classrooms and its impact on early literacy instruction at this point in time, but the possibility to improve skill attainment for young children with disabilities is promising.

\section{Traditional Instruction in Early Childhood}

Traditional education within early childhood settings incorporates the use of a blend of child-directed and teacher-directed learning opportunities that reflect developmentally 
appropriate practice for all learners within the early childhood classroom (NAEYC, 2009). This philosophy considers the needs, strengths, weaknesses, and individuality of all children participating in the early childhood classroom. Children are encouraged to explore and engage in their environments, with their peers, and with their teachers (Copple \& Bredekamp, 2009). Early childhood teachers provide learning experiences, such as stories, centers, and group activities, that reflect the class's combined interests, purposeful and constructive play opportunities, social emotional development, and quality adult interactions (Dodge, Heroman, Colker, \& Bickart, 2010).

According the NAEYC position statement on developmentally appropriate practice (2009), teachers are tasked with providing young learners with the most appropriate learning opportunities to help bridge the achievement gap that exists for young children upon entering kindergarten due to the increase in mandated accountability from lawmakers. One key area highlighted within the position statement refers to the area of early literacy development for children entering kindergarten. The report identifies that early childhood classrooms are not meeting the demands placed upon them to ensure the future reading success for young children.

Early literacy encompasses multiple areas, but most importantly the areas of phonemic awareness, print knowledge, and alphabet knowledge (Invernizzi, et al., 2004). These skills provide the foundations upon which reading achievement and writing proficiency occur and development of these skills serve as a predictor for future success (Justice et al., 2003). Phonemic awareness refers to the ability to attend to and manipulate phonemes, the distinct unit of sound within language, within words spoken orally (Heggerty, 2010). Print knowledge refers to the organization of print and how it is used to convey meaning (Heroman \& Jones, 2010). 
Alphabet knowledge refers to the ability to identify specific shapes of letters, name them, and related them to their respective sound (Johnston et al., 2015).

Alphabet knowledge is the single most important predictor of later reading success for young children (Johnston et al., 2015). The more familiar with the letters and their respective sounds and the ways in which children distinguish between them creates the foundations of understanding and interpreting words, both in written and oral context. This correspondence between letters and their sounds to create written and spoken words is the alphabetic principle (Heroman \& Jones, 2010). In letter acquisition, children are more likely to identify letters if they are in their name and eleven times more likely to know a letter if it is in the initial position in their name though there is not a specific developmental sequence to learning letter names (Phillips, Piasta, Anthony, Lonigan, \& Francis, 2012). This may be due in part to the emphasis of an uppercase letter in the beginning of a word and children obtaining uppercase letter identification before lowercase (Worden \& Boettcher, 1990).

Developmentally appropriate early childhood classrooms provide a print-rich environment where children can explore, activities that emphasize phonemic awareness and print knowledge, instances for children to identify alphabet letters, opportunities for stories to be read often, and a multitude of materials and opportunities for children to engage in their own efforts to write (Copple \& Bredekamp, 2009). The foundations of developmentally appropriate practice reside in the works of John Dewey, Jean Piaget, and Lev Vygotsky. Dewey (1897), an early philosopher on educational practice, was a proponent in the idea that children learned best through active exploration and experimentation. This idea was later corroborated with Piaget's work on cognitive development. Piaget (1972) acknowledged the importance of play for young children and the way in which it fostered logical, concrete thinking. Vygotsky (1978), who also 
supported the use of play in a child's development and the importance of the teacher-child relationship, posed that children could practice skills and social interactions through play which would allow the child to create more intricate ways of thinking.

Early childhood curricula are created and designed to provide developmentally appropriate practice based upon theory. Creative Curriculum ${ }^{\mathrm{TM}}$ is an example of an early childhood curriculum that provides guidelines to encourage child directed learning through inclusion of a variety of materials, print-rich environments, and studies that are guided and fueled by a child's interests, such as balls, trees, buildings, and bugs (Dodge, Heroman, Colker, \& Bickart, 2010). Interest areas and large group activities are planned around the study being implemented and quality literature is provided for the study. Additional materials may be added to address specific areas of need or to meet goals or standards.

When quality literature is provided through early childhood curricula, such as Creative Curriculum $^{\mathrm{TM}}$ and High Scope ${ }^{\mathrm{TM}}$, supplemental instruction and activities can be added to create a complete picture in early literacy. In the early childhood classroom, early literacy interventions are provided through direct instructional activities that take place during center times, small group, or whole group instruction being provided by a teacher in addition to child directed exploration (Heroman \& Jones, 2010; Justice et. al., 2003). These activities target specific skills and deficits to individual children are identified and indicated through assessment and screenings in early education (Invernizzi, Landrum, Teichman, \& Townsend, 2010). Though no definitive order of letter acquisition has been identified through research, children are more likely to learn letters that have specific meaning to them, such as a first initial, letters that have similar structure to other letters they have learned, letters that begin in the first half of the alphabet in comparison 
to the last half, and letters that correspond to the developmental progression of phonemes, such as B, D, M, H, N, P, and W (Justice, Pence, Bowles, Wiggins, 2006).

\section{Role of Technology Developing Early Literacy}

The availability and functionality of technology in today's classroom creates a powerful tool to reach all learners. In a joint position statement, the Fred Rogers Center and the National Association for the Education of Young Children (NAEYC) identified the influence and power technology yields on young learners and worked to jointly to create a set of guidelines reflecting best practice for the use of technology in the early childhood classroom (Donohue \& Schomburg, 2017; NAEYC \& Fred Rogers Institute, 2012). Both organizations indicated that quality of what is being presented should be considered for all children and technology should never replace creativity, exploration, and imaginative play. The use of technology and programming should always provide young users the ability to make choices and create learning on their own terms through the device or program (Beschorner \& Hutchison, 2013).

Research is used to guide and instruct practitioners on the best ways to educate and support learners. Evidence-based practices are strategies and interventions that are determined and supported by research to demonstrate the most effective outcomes for students (Wheeler, Mayton, \& Carter, 2015). Video modeling is a widely used evidence-based practice for children with autism spectrum disorders and other developmental disabilities to teach a variety of skills, but most commonly social emotional development and appropriate behavior. Computer-assisted instruction (CAI) is recognized as an evidence-based practice for providing a variety of instruction to students with autism spectrum disorders and other disabilities (National Professional Development Center on Autism Spectrum Disorder, 2015). CAI incorporates a variety of platforms and methods for teaching skills through tablets, computers, and other 
devices. When compared to video modeling, the use of CAI encompasses all academic and developmental areas, but most commonly reflects academic skills in children ages three through eighteen years of age.

CAI is used regularly within early childhood classrooms (Vernadakis, et al., 2005). A variety of recent studies on the uses of CAI in preschool across different skill and developmental areas, such as early literacy, mathematics, and science, have produced varying results. Researchers examining a two specific CAI programs, Imagine Learning and Waterford Early Learning, for teaching early literacy skills, including phonemic awareness, found that there was no difference in the acquisition of early literacy skills when the CAI programs were introduced to students from low socioeconomic backgrounds as compared to the control group, which received no intervention (Trotti, Hendricks, \& Bledsoe, 2017). The examiners attributed the lack of improvement in early literacy skills to the difficulty of the program itself and extraneous events outside of the study parameters. Akcay (2016) positive relationships were identified when science was studied within the context of CAI. Implementing CAI to explore the changing seasons for students who do not naturally experience all four seasons due to geographic locations was found to effective in comparison to traditional teaching. Finally, children who were identified as at-risk for failing to develop or low achievement in early literacy (Macaruso \& Rodman, 2011) and mathematic skills (McManis \& McManis, 2016) made significant achievements in the respective areas when a CAI program was implemented.

\section{TeachTown Basics ${ }^{\mathrm{TM}}$}

TeachTown Basics ${ }^{\mathrm{TM}}$ is a CAI program that is based upon the principles of applied behavior analysis instruction to provide meaningful instruction to students with developmental ages of 2 through 10 (Whalen, Massaro, \& Franke, 2008). The program is targeted for children 
with autism spectrum disorder and other developmental and intellectual disabilities. The program consists of a computer-based module or lesson and an additional teacher-led portion. Skill areas covered include adaptive skills, cognitive skills, language arts, language development, mathematics, and social emotional skills (TeachTown, 2010). The program itself will adjust content based upon a user's performance and specific skills can be isolated by facilitators to emphasize areas of need (Jones, Wilcox, \& Simon, 2015). TeachTown Basics $^{\mathrm{TM}}$ can generate data which can be used in the development of additional goals and instructional programming.

Limited research can be identified regarding TeachTown Basics ${ }^{\mathrm{TM}}$ focused on young children ages 3 through 5. Most relevant is a study by Whalen, et al. (2010) that consisted of 47 students, ages 3 through 6 , with autism spectrum disorders in across 4 elementary schools in a self-contained special education setting. Of the 47 students, 22 received the TeachTown Basics $^{\mathrm{TM}}$ intervention and the remainder served as the control group. The study showed that the majority of students who used TeachTown Basics ${ }^{\mathrm{TM}}$, in its entirety, for approximately 20 minutes a day across 3 months made statistically significant gains in the areas of cognitive skills, communication, social understanding, and life skills.

\section{Summary and Research Questions}

Early literacy skills are the first steps towards reading. The use of traditional teaching in early childhood classrooms has proven to not be an effective means of instructing young learners with disabilities (Goldstein et al., 2017), which includes alphabet identification. Studies have shown that CAI produces positive results in early childhood classrooms and for children with specific diagnoses, but limited research of how these instructional methods impact young children with unspecified diagnoses in inclusive settings. The study addressed the following research questions: (a) What is the difference between the rate of letter acquisition between CAI 
intervention and traditional teaching methods for young children with disabilities? (b) What is the efficacy of retention of letter recognition when comparing traditional teaching methods and CAI interventions?

\section{Method}

\section{Participants}

Six participants were randomly selected from an inclusive early childhood classroom of fourteen preschoolers who ranged in age from three to five years old. The school was selected because of the relationship between the examiner, administration, and staff. Consent to participate in the study was sent out to all students in the classroom and participants were randomly selected from students who returned parental consent. From a pool of 11 participants with confirmed parental consent, the first selection criteria was students with current IEPs. If too few participants with consent met this criteria, additional criteria in the following order were: (a) an identified academic need, such as referral for special education, (b) low socioeconomic status, (c) age, and (d) gender (i.e. if one sex was underrepresented within the sample).

Five of the participants were currently served under an IEP and one had been referred to the student assistance team for academic concerns. All participants were English speaking and attended a full day inclusive preschool program. All participants had passed vision and hearing screenings with normal results as part of their well-child screening provided by their pediatricians and were able to follow one-step directives. All participants had recently participated in the Phonological Awareness and Literacy Screening (PALS) assessment, specifically in the area of Uppercase Letter Knowledge (Appendix A). Pseudonyms were used for all participants. 
Cameron was a four-year-old male has an IEP under the classification of developmental delay. He did not have a specific medical or psychological diagnosis. Cameron qualified for the classification due to developmental delay in the areas of communication, adaptive, cognitive, and personal social skills. In addition to services provided by a developmental delay preK teacher, Cameron received speech language therapy and occupational therapy. His initial PALS scores in the area of Uppercase Alphabet Letter Recognition indicated that he knew 4 uppercase letters, C, O, X, and S. According to the PALS Quick Check completed before the study began, he correctly identified $6, \mathrm{C}, \mathrm{O}, \mathrm{X}, \mathrm{S}, \mathrm{B}$, and $\mathrm{G}$.

Hannah was a five-year-old female who also has an IEP in the area of developmental delay and would be transitioning to kindergarten the next school year. She did not have a specific medical or psychological diagnosis. Hannah initially qualified for the classification of developmental delay due to delays in the areas of communication, adaptive, and cognitive skills. In addition to receiving services provided by a developmental delay preK teacher, Hannah also received speech language therapy. However, Hannah was evaluated for special education services in kindergarten around the time of the study and only qualified for related services in speech therapy when she moved forward. Both of Hannah's initial PALS and the PALS Quick Check indicated that she did not correctly identify any uppercase alphabet letters.

Kylie was a three-year-old female who currently has an IEP in the area of developmental delay. She did not have a specific medical or psychological diagnosis, but qualified for the classification of developmental delay with a $25 \%$ or more delay in the areas of personal-social and adaptive domains. Kylie's initial PALS and PALS Quick Check scores indicated that she did not identify any uppercase alphabet letters. 
Katie was a three-year-old female, who turned four during the course of the study, who had an IEP for developmental delay. She did not have a specific medical of psychological diagnosis, but demonstrated delays in the areas of communication, adaptive, cognitive, and fine motor skills. Katie received speech language therapy in addition to services provided by a developmental delay preK teacher. Katie's initial PALS and her PALS Quick Check scores showed that Katie did not currently identify any uppercase alphabet letters.

Serenity was a four-year-old female who currently has an IEP under the label of developmental delay. She had no specific medical or psychological diagnosis but qualified for developmental delay in the areas of communication, adaptive, and personal social skills. In addition to receiving services provided by a developmental delay preK teacher, Serenity received speech language therapy and was referred for an additional evaluation for occupational therapy during the time of the study. Both Serenity's initial PALS and PALS Quick Check revealed that she did not currently identify any uppercase alphabet letters.

Sara was a 4-year-old female who did not have an IEP, but had been referred to the school's student assistance team for further evaluation due to concerns in cognitive and fine motor skills by her teacher. She had no known diagnoses. Sara was going to be transitioning to kindergarten in the fall and as of the time of the study, she had not been evaluated for special education services. Sara's initial PALS indicated that she did not correctly identify any uppercase alphabet letters and her PALS Quick Check indicated she identified 3 uppercase alphabet letters, $\mathrm{O}, \mathrm{S}$, and $\mathrm{X}$. 


\section{Setting}

The study was conducted in a PreK through $5^{\text {th }}$ grade public school that was situated in a small urban setting and receives Title I funds for the students served. Approximately $77.8 \%$ of the student population received free and reduced lunch. The study took place in the preschool classroom during part of the typical school routine. Specifically, the study took place before and after lunch times during free choice centers.

The teacher held valid dual certification in early childhood special education and early childhood education and had 3 years of experience working with preschoolers. The classroom could house approximately eighteen students, nine receiving early childhood special education services and nine who did not receive special education services. However, this classroom was not filled to capacity during the study with the class being made up of 7 students with special needs and 7 without. The classroom was approximately 700 square feet with a variety of appropriately sized furniture for young children that included shelving for toys, books, blocks, and manipulatives, 3 trapezoid shaped tables, a kidney-shaped table, a kitchen play center, and sensory tables. The classroom followed a West Virginia state mandated curriculum, Creative Curriculum $^{\mathrm{TM}}$, which addresses all developmental areas (e.g. adaptive, personal-social, fine motor, gross motor, cognitive, and communication skills). The students participated in small group, large group, and individualized instruction throughout the day with the supports provided by the teacher and early childhood certified assistant teacher.

\section{Materials}

The computer assisted instruction, Teach Town Basics ${ }^{\mathrm{TM}}$, was presented to the students as a treatment, via for each of the participants. In addition, individual on-ear headphones for each participant were used with the iPads. The PALS screening tools materials and online 
computer scoring were used as a pretest and posttest measure. The comparison treatment incorporated business-as-usual classroom instruction, including manipulations, teacher made, and commercially made uppercase matching letter games, alphabet tracing activities, alphabet manipulatives, and letter puzzles (Appendix B) that were in accordance with developmentally appropriate activities and suggestions found in Creative Curriculum ${ }^{\mathrm{TM}}$. Randomized uppercase letter probes were created by the researcher on individual 3 x 5, index sized tagboard cards using Century Gothic, 80-point font (Appendix C). A video camera was used to record all sessions.

\section{Variables}

The first independent variable was the Teach Town Basics $^{\mathrm{TM}}$ curriculum, which is a CAI program that uses discrete trial training to teach a variety of skills and identify targeted alphabet letters (i.e. D, H, I, R, T) for this study. The program prompts the student to select a letter from an array of letters and the student must select the correct response. Initially, the array consists of the same set of letters and changes to different letters and numerals as the student becomes more proficient. If the child selects an incorrect response multiple times, the number of correct options will be limited until there is only the correct response is left. After 3 to 5 questions, a 30 second video or mini-game appears as a reward or reinforcement. Teach Town Basics ${ }^{\mathrm{TM}}$ allows users to adapt and construct learning that is appropriate for each user.

The second independent variable was traditional teaching methods and activities including a matching uppercase to uppercase letter game, letter manipulatives, letter puzzles, and tracing letter activities as supported through the Creative Curriculum ${ }^{\mathrm{TM}}$. During free choice center time, children select an activity out of several choices provided by the teacher. The teacher and assistant teacher support the chosen activity by working alongside the child, asking open ended questions, and providing information related to the activity in an effort to guide a 
child's learning based upon their interest. For the purpose of this study, activities and manipulatives using targeted letters (i.e. $\mathrm{U}, \mathrm{N}, \mathrm{J}, \mathrm{Y}$, and $\mathrm{Q}$ ) were during the traditional teaching condition.

The dependent variable of the study was the rate of receptive alphabet letter identification of previously unknown letters. In both traditional teaching and CAI conditions, participants identified uppercase alphabet letters by pointing using a standard, randomized probe of the five letters occurring 5 times for each particular session and was recorded by the examiner. Five targeted letters were presented to the participant at a time. An example of the exchange included

"Show me the ___ for all designated letters and the participants were given up to 15 seconds to respond. The cards were then shuffled and presented to the participant again for a total of five times. Both interventions occurred daily for a total of 10 probes daily. No feedback was given for correct or incorrect responses. For the purposes of this study, the program parameters allowed the participants to access only the lessons focused on the letters targeted and the standard prompting hierarchy set in Teach Town Basics ${ }^{\mathrm{TM}}$.

\section{Measures}

PALS was used as a pretest and posttest to assess each participant's ability to identify uppercase alphabet letters. The PALS contains items assessing letter knowledge, name writing, letter sound knowledge, beginning sounds, rhyming, nursery rhyme awareness, and print awareness (Invernizzi, et al., 2004). Typically, the full PALS is completed during the Fall and Spring of the school year, but PALS Quick Checks can be completed throughout the year in a specific area if needed. All students participated in a complete screening at the beginning of the school year and a PALS Quick Check completed only on uppercase alphabet letter recognition prior to the beginning of the study (Appendix B). 
An additional randomized uppercase alphabet letter probe for the five letters of focus created by the researcher was administered during the Preintervention and Intervention phases, daily for five probes. The targeted letters for the CAI intervention were selected from the letters previously unknown to the student and the letter groupings provided through Teach Town Basics $^{\mathrm{TM}}$ lessons. The traditional teaching letters were selected from letters previously unknown to the student and letters that were not the same as the beginning letter of any participant. To randomize the letters for each probe, the cards were shuffled after each probe. After all phases were complete, each student completed the PALS End of the Year as part of their spring assessments. Only the uppercase alphabet letter recognition portion was used as a posttest. The Teach Town Basics ${ }^{\mathrm{TM}}$ Progress Report was used to identify overall progress of the participants with regards to lesson completion and lesson mastery.

\section{Procedures}

\section{Experimental Design}

A concurrent treatment single case design was used to compare the difference in the rate of acquisition of uppercase letter knowledge between computer assisted intervention (T1) and traditional teaching practices (T2). The rapid alternation between treatments helps to avoid internal threats to validity such as maturation or history. Randomization of participants to treatment condition aided in avoiding sequencing effects.

The design was comprised of the preintervention, intervention, and maintenance phases. Each treatment session was comprised of approximately 10 minutes of instruction via T1 and 10 minutes of the T2 occurring sequentially in random order. The length of the sessions was selected to reflect the average attention span of children ages 3 to 4 years old. Practitioners suggest the attention span to be 3 minutes per every year of age for a child (Salcedo, 2018). 
Prior to the beginning of the study, the teacher and assistant teacher received two 45 min sessions on the requirements and parameters of the study by the researcher. These sessions included how TeachTown Basics ${ }^{\mathrm{TM}}$ would be used, the center activities to present to the students during centers, data collection, and how the probes would be incorporated. The teacher was asked to avoid explicitly teaching any letters or letter sounds during the study. If any unintentional teaching occurred at the school, such as a child asking what a particular letter might be and the teacher providing an answer, the teacher and assistant teacher were asked to document the letter and with what participant or participants it occurred.

Targeted letters were selected from previously unknown uppercase alphabet letters indicated on the PALS Quick Check and Preintervention phase. Specifically, the 5 letters in the targeted letter group for T1 (i.e. D, T, H, I, R) were comprised of letters that do not hold similar structural characteristics, were not the initial letter of the participants' first names, occurred within the developmental sequence of phoneme acquisition in a group and were within the sequence of the letters and lessons taught through the CAI program. The 5 letters selected for T2 (i.e. U, N, J, Y, and Q) were comprised of letters without similar structural characteristics that were not the initial letter of the participants' first names.

\section{Baseline}

During the baseline data phase, no letter recognition instruction took place. Participants were provided table activities for 10-minutes that did not include letters and iPads with games that did not reinforce letter knowledge on the trapezoid tables located in the classroom. At the end of each 10 minute session, the examiner conducted probes at the kidney-shaped table and recorded data for the number of correct letters identified utilizing the randomized letter probe for 5 consecutive probes. Each of the probes consisted of 5 uppercase alphabet letters not previously 
known to the participant, according to the PALS Quick Check, on index-sized tagboard cards.

The examiner would shuffle the cards and present all five to the participant and ask, "Show me the (name of letter)" for each targeted uppercase letter. The examiner marked a plus for a correct response and a minus for an incorrect response. The baseline data helped to determine the selection of targeted letters by identifying and corroborating previously unknown letters with the PALS Quick Check.

\section{Interventions}

The two treatments (i.e. T1, T2), were randomly assigned by the examiner by using the randomizer app on the iPad. The first three participants received the $\mathrm{T} 1$ intervention first and the last three received the $\mathrm{T} 2$ intervention first for that day. A chart indicating the schedule of when participants received each treatment is located in Appendix F. Following the completion of the first intervention (i.e. T1, T2), the participant received the probe for the intervention and then participated in the comparison treatment followed by a probe. Each intervention session lasted for approximately 10-minutes. For the Teach Town Basics ${ }^{\mathrm{TM}}$ intervention (T1), students participated using iPads at the kidney-shaped table in the back of the classroom. The teacher introduced the lesson by saying "Come with me (student name). It is time to work" and then presented the iPad, logged into the appropriate lesson for the day beforehand, to each student at a table where the examiner remained with the participants. The Teach Town Basics ${ }^{\mathrm{TM}}$ program allowed a specific time, $10 \mathrm{~min}$., to be set for each participant. At the end of the session, the program would stop and project a picture of a town at sleep indicating the session was over. The first group 5 uppercase alphabet letters not previously known by the individual were the same for all 6 participants and were comprised of the letters D, T, I, H, and R. These were selected in accordance to the letter selection criteria noted in the experimental design section as determined 
by the PALS Quick Check and Preintervention phase and were introduced during the first session and continued until students had achieved a mastery criterion of $80 \%$ for each of the 5 letters. The post-intervention, randomized probe was administered to the participants by the examiner, shuffling the cards for each probe. As the teacher and examiner completed each step, they checked off a scripted list of items for the daily TeachTown Basics ${ }^{\mathrm{TM}}$ intervention (Appendix G) daily that was submitted with the randomized probes for each student daily.

The traditional teaching activity (T2) was comprised of typical child-directed letter exploration provided through hands-on center type activities as dictated through the Creative Curriculum $^{\mathrm{TM}}$. Prior to the session beginning, the teacher set out materials on trapezoid tables within the classroom that reflect the 5 target letters, $\mathrm{U}, \mathrm{N}, \mathrm{J}, \mathrm{Y}$, and Q for that session. Materials consisted of matching letter file folder games, letter exploring bean bags, tactile letter tracing, and other activities the teacher would typically use that reflect the same skills that are taught through traditional preschool instruction in letter knowledge. Materials provided only reflected the targeted letters for the participants. In addition, other centers within the classroom were available for the students, such as blocks and dramatic play. The teacher followed the scripted procedure asking the children to come to work and monitored the children during the 10-min session. As with traditional preschool settings, the children were not required to stay at the table with the materials if they choose not to do so. Thus, the examiner tracked how much time each child spent interacting with the activities. The five randomized probes were given to the participants upon the conclusion of the intervention by the examiner, with the examiner shuffling the cards in between each probe. The children would move on to the next set of letters when $80 \%$ mastery of each letter of the five letters had occurred. As the teacher and examiner 
completed each step, they checked off a scripted list of items (Appendix H) completed daily that was submitted with the randomized probes for each student daily.

\section{Maintenance}

A maintenance phase began immediately after the interventions had ended. The treatment determined to be most effective during the intervention phase would used during the maintenance phase for 10 min on a set of 5 letters not previously used, letters A, E, M, V, and Z. Teach Town Basics ${ }^{\mathrm{TM}}$ was implemented for six additional sessions following the same procedural guidelines as listed above. The examiner followed through with five randomized probes with participants in the same procedure noted above.

\section{Interobserver Agreement}

All sessions during the preintervention, intervention, and maintenance phases were videotaped and coded afterwards by professionals within the field of early childhood special education from the Office of Special Programs, familiar with the assessments used and completing observations and who were not aware of the direct purpose of the study to determine interobserver agreement (IOA). These professionals had discussed the method of observing the videos with the researcher. In addition, sample videos, from another classroom, were shown to the observers and rated separately and then together to discuss differences and insure agreeability. Using a checklist (Appendix D), the observers scored student responses to determine the interobserver agreement (IOA). The IOA was calculated by adding the total number of agreements, dividing them by the total number of agreements and disagreements, and multiplying by 100 . IOA was collected from $30 \%$ of randomly selected sessions from each phase. An IOA of less than $90 \%$ would be unacceptable for the study. A total of 155 sessions were documented across all participants and 47 random examples were identified for IOA. The 
total number of agreements among both observers is 47 and the total number of agreements and disagreements was 47 for an IOA of $100 \%$.

\section{Procedural Fidelity}

From the videotaped sessions, the same professionals used to determine the IOA were used to complete the same researcher created checklist listing procedures as the teacher and examiner completed (Appendix $\mathrm{G}$ and $\mathrm{H}$ ). A sample video of another classroom was given to the observers to score and to check for agreement between observers. Procedural fidelity was calculated by the total number of "yes" responses divided by the total of "yes" and "no" responses multiplied by 100 . The checklists were completed on every intervention; criterion was set at $85 \%$. If procedural fidelity was below the criterion, both observers and the researcher would review and discuss the video until a consensus was reached and additional retraining would occur on non-study observations. For the study, 31 sessions were completed among all phases. The total number of agreements was 30 and the total number of agreements and disputes was 31 for a procedural fidelity of $96.77 \%$

\section{Social Validity}

The social validity of the goals and outcomes of the study was evaluated through a questionnaire (Appendix I) completed by the teacher and assistant teacher who work in the classroom. The questionnaire was based upon a six-point Likert scale and consisted of statements regarding perceptions on the efficacy, convenience, and appropriateness.

To determine the effectiveness of each intervention, ach data point was plotted daily after the session took place. Reflective of a concurrent treatment schedule design, data from each intervention was graphed together in separate data paths on the same graph. Tables 2 through 7 list number of correct responses for each letter for both $\mathrm{T} 1$ and $\mathrm{T} 2$ for each participant. These 
tables reflect the correct number of times a letter was identified during the probes for T1 and T2. Figures 1 through 6 represent the mean average of correct responses across all phases. In addition, changes between pretest and posttest scores in Table 8 reflect growth according to the PALS Quick Check and End of the Year assessment.

\section{Data Analysis Plan}

Letter acquisition was evaluated through visual analysis of graphed data to determine differences between treatments and variations among the identified phases. Level of responding was determined by the mean of each session. Trend, or slope, identified the direction and rate of change within the intervention phase. Variability assessed the range or standard deviation that occurs within the data. A functional relationship was established when visual analysis confirmed a separation of the data paths, with higher level of performance evident in one of the treatment conditions. External validity was supported via replication of the effect.

Visual analysis of the data supported the use of the Teach Town Basics ${ }^{\mathrm{TM}}$ program to support young children with disabilities in acquiring letter recognition in comparison to child directed learning that is supported through policy and mandates for most young learners.

\section{Results}

\section{Cameron}

According the data compiled from the Teach Town Basics ${ }^{\mathrm{TM}}$ program, Cameron was the only participant who demonstrated mastery over the 2 lessons selected during the T1 intervention. Visual analysis of Figure 1 also reveals a change in the level and trend during the T1 condition and he successfully identified 3 letters, I, H, and R, with 100\% accuracy as of his last session, which is found on Table 2. His mean percentage of correct responses for T1 
intervention was $45.78 \%$. For the $\mathrm{T} 2$ intervention, no change in level was noted upon visual analysis and his mean percentage of correct responses was $20.44 \%$. Of the 10 sessions, Cameron selected to participate in the teacher directed activities $30 \%$ of the time and chose to participate in other nonrelated activities or centers, such as blocks and dramatic play, the other times.

During the maintenance phase, Cameron added 1 additional letter, Z, with $80 \%$ accuracy. From Cameron's PALS Quick Check prior to both interventions, Cameron correctly identified 6 uppercase alphabet letters. At the end of the study, Cameron correctly identified 11 uppercase alphabet letters on his end of the year PALS screening, an increase of 5 letters in comparison. All of the 5 additional letters were the same as were targeted through TeachTown Basics ${ }^{\mathrm{TM}}$. Hannah

Hannah, according to the Teach Town Basics ${ }^{\mathrm{TM}}$ data did not successfully complete any lessons in the program. Visual analysis reveals no change in level or trend with the T1 or T2 interventions on Figure 2. Her mean percentage of correct responses for T1 and T2 was $14.5 \%$ and $15.5 \%$, respectively. During the maintenance phase of the study, Hannah correctly identified the letter A with $100 \%$ accuracy. Of the 10 sessions, Hannah selected to participate in the child directed T2 activities $60 \%$ of the time. Writing samples collected from Hannah during the T2 intervention demonstrated an interest in the activities and emerging hand-eye coordination (Appendix J), but visual analysis does not indicate a change in level, trend, or variability. From Hannah's PALS Quick Check, she correctly identified 0 uppercase alphabet letters and on her end of the year PALS assessment, she correctly identified 1 uppercase alphabet letter, A, which was taught by TeachTown Basics ${ }^{\mathrm{TM}}$ during the maintenance phase. 
Kylie

Kylie, according to the Teach Town Basics $^{\mathrm{TM}}$ program data, achieved mastery on one lesson through the program. Visual analysis revealed an increasing trend during the T1 phase, where she successfully identified the letter R with $100 \%$ accuracy on Figure 3 . Upon further inspection of the data, Kylie achieved $60 \%$ accuracy on identifying the letters A and E through the maintenance phase. Her mean percentage of correct responses for T1 was $21.33 \%$. The visual analysis of the $\mathrm{T} 2$ data does not indicate a change in level and her mean percentage of correct responses was $20 \%$. Kylie selected the T2 activities 1 time out of 6 sessions. It is important to note that during the course of the study, Kylie broke her leg half way through the intervention phase and missed a total of 10 days from school, which limited her participation in the study. On Kylie's PALS Quick Check, she correctly identified 0 uppercase alphabet letters and on her end of the year PALS assessment, Kylie correctly identified 3 uppercase alphabet letters, R, E, and A, which were all targeted letters from TeachTown Basics ${ }^{\mathrm{TM}}$. Katie

Katie, according to the Teach Town Basics $^{\mathrm{TM}}$ program data, did not successfully master either of the targeted lessons. Visual analysis for both $\mathrm{T} 1$ and $\mathrm{T} 2$ data does not indicate a change in level on Figure 4. Katie's mean percentage of correct responses for T1 and T2 was 19.2\% and $21.2 \%$, respectively. Katie selected the T2 child directed activities $80 \%$ of the time. On Katie's PALS Quick Check, she correctly identified 0 uppercase alphabet letters and on her end of the year PALS assessment, Katie correctly identified 0 uppercase alphabet letters. It is important to note that Katie would indicate or touch her responses in order from right to left regardless of letter on the card. 
Serenity

Serenity, according to the Teach Town Basics ${ }^{\mathrm{TM}}$ program data, did not successfully master either of the 2 targeted lessons. Visual analysis of T1 and T2 data does not reflect a change in trend for either intervention on Figure 5. The mean percentage of correct responses for Serenity's T1 and T2 was $17.77 \%$ and $17.33 \%$, respectively. Of the 10 sessions for the T2 intervention, Serenity selected the child directed activities $60 \%$ of the time. As with Hannah, Serenity demonstrated an interest in the T2 activities as evidenced on student work sample (Appendix J), but did not generalize the information for the purposes of this study. Serenity's PALS Quick Check revealed she correctly identified 0 uppercase alphabet letters and her end of the year PALS assessment revealed she correctly identified 0 uppercase alphabet letters. Sara

Sara, according to the Teach Town Basics ${ }^{\mathrm{TM}}$ program data, did not successfully master either of the 2 targeted lessons. However, visual analysis of T1 data reflected a slight increase in trend for the intervention on Figure 6. Sara correctly identified the letter H with $100 \%$ accuracy. Upon further examination of the data, Sara missed 4 of 10 sessions. By the end of the study, she was correctly identifying the letter T with $60 \%$ accuracy which is found on Table 7 . Further exploration into the maintenance phase data indicates that Sara was correctly identifying the letters $\mathrm{A}$ and $\mathrm{Z}$ with $80 \%$ accuracy by the end of the study. Her mean percentage of correct responses on $\mathrm{T} 1$ was $34 \%$. Visual analysis of the T2 data revealed no change in trend or level. Out of the 6 sessions, Sara did not participate in the T2 activities of her own choice. Her mean percentage of correct responses for T2 was 22.67\%. Sara's PALS Quick Check indicated that she correctly identified 3 uppercase alphabet letters $(\mathrm{O}, \mathrm{S}$, and $\mathrm{X})$ and on her end of the year PALS assessment, she correctly identified 7 uppercase alphabet letters (O, S, X, H, T, A, and Z). 
The additional letters Sara was able to identify were all targeted letters during the T1 intervention and maintenance phases.

Both interventions were provided for approximately 10 -minutes per session. The total mean usage time for the CAI program during T1 intervention and maintenance was 2.13 hours the total mean usage time for the T2 instruction was approximately 1.67 hours.

From the questionnaire to determine social validity, responses from the teacher and assistant teacher were analyzed to determine the appropriateness of the intervention for the featured classroom. Both the teacher and assistant teacher felt that Teach Town Basics ${ }^{\mathrm{TM}}$ was a beneficial addition to their classroom. They both felt it was appropriate for the learning of the targeted students for the specific skills and would be interested in using it to target other skills. Both felt that this CAI program would be beneficial for other early childhood teachers and other students.

\section{Discussion}

A concurrent treatment single case design across the intervention phase was used to compare the rate of acquisition of uppercase letter knowledge between computer assisted intervention and traditional teaching practices with six young children with and without disabilities in an inclusive early childhood setting. During the intervention, the participants used the CAI program, Teach Town Basics ${ }^{\mathrm{TM}}$ to learn 5 targeted uppercase alphabet letters and were offered a variety of teacher-created, child-directed activities focusing on a different set of 5 targeted uppercase alphabet letters. Four of the students demonstrated an increase in letter acquisition with the CAI program in comparison to the traditional teaching opportunity.

Results obtained from the study were similar to existing studies using CAI programs to improve knowledge for young children with disabilities. (Chai, Vail, \& Ayers, 2015; Macaruso 
\& Rodman, 2011; McManis \& McManis, 2016; \& Trotti, Hendricks, \& Bledsoe, 2017). Four of the students, Cameron, Kylie, Hannah, and Sara, made some positive gains throughout the study, though gains were inconsistent. Cameron was able to identify 5 additional letters on his PALS End of the Year assessment, which was the most significant growth and all letters were those targeted by TeachTown Basics ${ }^{\mathrm{TM}}$. Results from the individual probes and the PALS assessment data support the efficacy in regard to letter acquisition of the CAI intervention in direct comparison to the traditional teaching methodology in early childhood settings for young children with disabilities.

The traditional teaching did not produce any increased letter acquisition in the participants, but few of the participants demonstrated interest in the activities. When given a choice between activities, participants selected activities such as dramatic play or blocks more often. However, Hannah and Serenity produced work samples (Appendix J) that demonstrated an interest in the T2 activities, such as roll and write. Hannah's sample shows where Hannah has written all of the targeted T2 letters. Serenity's sample from the same activity provides the letters $\mathrm{J}, \mathrm{Y}$, and Q.

Some of the variability among differences in the individual results of the participants can be attributed to student attendance and the number of sessions completed. Of the 6 participants, only 1 student, Katie, did not miss a day of school during the intervention phase, whereas Kylie missed 4 of the 10 days during the intervention phase. It is important to note that the average use of the TeachTown Basics ${ }^{\mathrm{TM}}$ program was only 2.13 hours and the average school day is 7.5 hours per day. It is likely more robust results would be identified with consistent implementation and increased time using the program. In the study by Whalen et al. (2010), participants used TeachTown Basics ${ }^{\mathrm{TM}}$ for 20-minutes a day for 3 months and demonstrated statistically 
significant gains. Dosage is key when considering the gains made by the participants.

Traditional teaching may have also proved more successful if the amount of time spent was increased from the 1.67 hours. The more repetition of the targeted letters may have garnered move significant results.

\section{Limitations}

Teach Town Basics ${ }^{\mathrm{TM}}$ provides users with additional lessons to generalize the content being taught through the program into the classroom. This feature is important in the continuation of learning that occurs through the program to the world in general. With the parameters of study being set upon approval from the Institutional Review Board (IRB) and access to the full program limited until the study began, these lessons for further generalization were not instituted. These additional lessons could have impacted letter acquisition of the T1 intervention but would not impact the $\mathrm{T} 2$ intervention data.

In addition, parental involvement is a factor that could not be accounted for during the course of the study. Parents were asked in the consent to avoid teaching of alphabet letters at home for the duration of the study, but there is no way to assess whether or not incidental teaching occurred. This outside influence could change the initial outcomes of the study.

\section{Recommendations for Further Study}

Teach Town Basics ${ }^{\mathrm{TM}}$ has a wealth of research supporting its efficacy and use as an evidence-based practice for work with children with developmental delay and autism spectrum disorder. The program incorporates features that allow the researcher to individualize the program to meet the needs of individual students, including reinforcement schedules and prompting hierarchies. The specific parameters for this study did not allow for adjustment to adapt the program to meet the individual needs of the participants during the study. As it is best 
practice to differentiate instruction to meet the individual needs of the student (NAEYC, 2009), further investigation is warranted to see if changes in these areas would change outcomes. Moreover, additional time to access the program may provide more significant results.

Traditional ways of teaching content for young children has significantly relied on a blend of child directed and teacher directed learning. Exploration of the efficacy of Teach Town Basics $^{\mathrm{TM}}$ in conjunction with these methods may prove to be a valuable resource for early childhood special educators. This additional support could be extended to a variety of areas covered through the Teach Town Basics ${ }^{\mathrm{TM}}$ programming, such as counting and cardinality, social skills, and other areas of early literacy.

\section{Conclusion}

Developmentally appropriate practice in the instruction of young children in early childhood settings has been the standard of practice across preschool settings. The inclusion of young children with disabilities into these settings has produced a challenge in reaching and meeting the needs of all young learners. Moreover, increased accountability and the introduction of standards in early childhood creates a difficulty for teachers when preparing all students for kindergarten. Introducing additional technology and instructional methods into inclusive environments may be a key in the success for all students. CAI programs, such as TeachTown Basics $^{\mathrm{TM}}$, generates a level playing field for learners in inclusive environments. More exploration into these tools for children with and without disabilities in inclusive settings is warranted to garner a clear picture of their potential use and effect. 


\section{References}

Beschorner, B. \& Hutchison, A. (2013). iPads as a literacy teaching tool in early childhood. International Journal of Education in Mathematics, Science, and Technology, 1(1), 1626.

Chai, Z., Vail, C. O., \& Ayres, K. M. (2015). Using an iPad application to promote early literacy development in young children with disabilities. The Journal of Special Education, 48(4), 268-278.

Copple, C. \& Bredekamp, S. (Eds.) (2009). Developmentally appropriate practice in early childhood programs serving children from birth through age 8. Washington, DC: National Association for the Education of Young Children.

Dewey, J. (1897). My pedagogic creed. The School Journal, 54(3), 77-80.

Dietze, B. \& Kashin, D. (2013). Shifting views: Exploring the potential for technology integration in early childhood education programs. Canadian Journal of Learning and Technology, 39(4). Retrieved from https://www.cjlt.ca/index.php/cjlt/article/view/26298/19480

Dodge, D. T., Heroman, C., Colker, L. J., \& Bickart, T. S. (2010). The Creative Curriculum for preschool, fifth edition: The foundation (Vol. 1). Bethesda, MD: Teaching Strategies.

Donohue, C. \& Schomburg, R. (2017). Technology and interactive media in early childhood programs: What we've learned from five years of research, policy, and practice. Young Children, 72(4), 72-78.

Goldstein, H., Olszewski, A., Haring, C., Greenwood, C. R., McCune, L., Carta, J., Atwater, J., Guerrero, G., Schneider, N., McCarthy, T., \& Kelley, E. S. (2017). Efficacy of a supplemental phonemic awareness curriculum to instruct preschoolers with delays in 
early literacy development. Journal of Speech, Language, and Hearing Research, 60(1), 89-103.

Heggerty, M. \& Turso, C. (2010). Phonemic awareness: The skills that they need to help them succeed! Prekindergarten version. River Forest, IL: Literacy Resources, Inc.

Herold, B. (2016, February 5). Technology in education: An overview. Education Week. Retrieved from https://www.edweek.org/ew/issues/technology-in-education/index.html

Heroman, C. \& Jones, C. (2010). The Creative Curriculum for preschool: Literacy (Vol. 3). Bethesda, MD: Teaching Strategies.

Horner, R. H. \& Spaulding, S. A. (2010). Single-subject design. In N. J. Salkind (Ed.), Encyclopedia of Research Design (pp.1387-1394). Retrieved from http://methods.sagepub.com.www.libproxy.wvu.edu/reference/encyc-of-researchdesign/n424.xml

Invernizzi, M., Landrum, T. J., Teichman, A., \& Townsend, M. (2010). Increased implementation of emergent literacy screening in pre-kindergarten. Early Childhood Education Journal, 37(6), 437-446.

Invernizzi, M., Sullivan, A., Meier, J., \& Swank, L. (2004). PALS PreK teacher's manual. Retrieved from https://pals.virginia.edu/public/pdfs/rd/tech/PreK technical chapter.pdf

Johnston, F., Invernizzi, M., Helman, L., Bear, D. R., \& Templeton, S. (2015). Words their way for preK-K. Upper Saddle River, NJ: Pearson Education.

Jones, P., Wilcox, C., \& Simon, J. (2015). Evidence-based instruction for students with autism spectrum disorder: TeachTown Basics. In T. A. Cardon (Ed.), Technology and the treatment of children with autism spectrum disorder (pp.113-129). New York City, NY: Springer. 
Justice, L. M., Chow, S., Capellini, C., Flanigan, K., \& Colton, S. (2003). Emergent literacy intervention for vulnerable preschoolers: Relative effects of two approaches. American Journal of Speech-Language Pathology, 12(3), 320-332.

Justice, L., Logan, J., Kaderavek, J., Schmitt, M. B., Tompkins, V., \& Bartlett, C. (2015). Empirically based profiles of the early literacy skills of children with language impairment in early childhood special education. Journal of Learning Disabilities, 48(5), 482-494.

Justice, L. M., Pence, K., Bowles, R. B., \& Wiggins, A. (2006). An investigation of four hypotheses concerning the order by which 4-year-old children learn the alphabet letters. Early Childhood Research Quarterly, 21(3), 374-389.

McManis, M. H. \& McManis, L. D. (2016). Using a touch-based, computer-assisted learning system to promote literacy and math skills for low-income preschoolers. Journal of Information Technology Education: Research, 15, 409-429.

Macaruso, P. \& Rodman, A. (2011). Efficacy of computer-assisted instruction for the development of early literacy skills in young children. Reading Psychology, 32(2), 172196.

National Association for the Education of Young Children. (2009). Developmentally appropriate practice in early childhood programs serving children from birth through age 8: A position statement. Retrieved from https://www.naeyc.org/sites/default/files/globallyshared/downloads/PDFs/resources/position-statements/PSDAP.pdf

National Association for the Education of Young Children \& Fred Rogers Center for Early 
Learning and Children's Media. (2012, January). Technology and interactive media as tools in early childhood programs serving children from birth through age 8 . Retrieved from https://www .naeyc.org/sites/default/files/globallyshared/downloads/PDFs/resources/topics/PS_technology_WEB.pdf

National Professional Development Center on Autism Spectrum Disorder. (2015). What EBPS have been identified? Retrieved from https://autismpdc.fpg.unc.edu/evidence-basedpractices

Odom, S. L., Buysse, V., \& Soukakou, E. (2011). Inclusion for young children with disabilities: A quarter century of research perspectives. Journal of Early Intervention, 33(4), 344356.

Phillips, B. M., Piasta, S. B., Anthony, J. L., Lonigan, C. J., \& Francis, D. J. (2012). IRTs of the ABCs: Children's letter name acquisition. Journal of School Psychology, 50(4), 461481.

Piaget, J. (1972). Play, dreams, and imitation in childhood. London: Routledge and Kegan Paul.

Salcedo, M. (2018). Uncovering the roots of challenging behavior: Create responsive environments where young children thrive. Minneapolis, MN: Free Spirit Publishing.

TeachTown. (2010). TeachTown Basics: Scope and sequence computer lessons. Retrieved from http://web.teachtown.com/wp-content/uploads/2015/10/Scope and Sequence OnComputer-Lessons-copy.pdf

Trotti, J., Hendricks, R., \& Bledsoe, C. (2017). Emergent literacy development and computer assisted instruction. SRATE Journal, 26(1), 30-39.

Vernadakis, N., Avgerinos, A., Tsitskari, E., \& Zachopoulou, E. (2005). The use of computer 
assisted instruction in preschool education: Making teaching meaningful. Early Childhood Education Journal, 33(2), 99-104.

Vygotsky, L. S. (1978). Mind in society: The development of higher psychological process. Cambridge, MA: Harvard University Press.

Whalen, C. Massaro, D., \& Franke, L. (2008). Generalization in computer-assisted intervention for children with autism spectrum disorders. In C. Whalen (Ed.), Real life, real progress for children with autism spectrum disorders: Strategies for successful generalization in natural environments (pp. 1-21). Baltimore, MD: Brookes Publishing Company.

Whalen, C., Moss, D., Ilan, A. B., Vaulpel, M., Fielding, P., Macdonald, K., Cernich, S., \& Symon, J. (2010). Efficacy of TeachTown: Basics computer-assisted intervention for the Intensive Comprehensive Autism Program in Los Angeles Unified School District. Autism, 14(3), 179-197.

Wheeler, J. J., Mayton, M. R., \& Carter, S. L. (2015). Methods for teaching students with autism spectrum disorders: Evidence-based practices. Boston, Massachusetts: Pearson.

Worden, P. E. \& Boettcher, W. (1990). Young children's acquisition of alphabet knowledge. Journal of Reading Behavior, 22(3), 277-295. 
Tables

Table 1

Characteristics of Participants

\begin{tabular}{|c|c|c|c|c|c|}
\hline Participant & Age & $\begin{array}{l}\text { IEP? Developmental } \\
\text { Areas Qualified? }\end{array}$ & $\begin{array}{l}\text { Specific } \\
\text { diagnosis? }\end{array}$ & $\begin{array}{l}\text { Related } \\
\text { Services }\end{array}$ & $\begin{array}{l}\text { PALS Quick Check } \\
\text { - Letters identified }\end{array}$ \\
\hline Cameron & 4 & $\begin{array}{l}\text { Yes; Communication, } \\
\text { Adaptive, Cognitive, and } \\
\text { Personal-Social Skills }\end{array}$ & No & $\begin{array}{l}\text { Speech } \\
\text { Therapy and } \\
\text { Occupational } \\
\text { Therapy }\end{array}$ & $\begin{array}{l}\mathrm{C}, \mathrm{O}, \mathrm{X}, \mathrm{S}, \mathrm{B}, \text { and } \\
\mathrm{G}\end{array}$ \\
\hline Hannah & 5 & $\begin{array}{l}\text { Yes; Communication, } \\
\text { Adaptive, and Cognitive } \\
\text { Skills }\end{array}$ & No & $\begin{array}{l}\text { Speech } \\
\text { Therapy }\end{array}$ & No letters \\
\hline Kylie & 3 & $\begin{array}{l}\text { Yes; Adaptive and } \\
\text { Personal-Social Skills }\end{array}$ & No & None & No Letters \\
\hline Katie & 3 & $\begin{array}{l}\text { Yes; Communication, } \\
\text { Adaptive, Cognitive, and } \\
\text { Fine Motor Skills }\end{array}$ & No & $\begin{array}{l}\text { Speech } \\
\text { Therapy }\end{array}$ & No Letters \\
\hline Serenity & 4 & $\begin{array}{l}\text { Yes; Communication, } \\
\text { Adaptive, and Personal } \\
\text { Social }\end{array}$ & No & $\begin{array}{l}\text { Speech } \\
\text { Therapy }\end{array}$ & No Letters \\
\hline Sara & 4 & $\begin{array}{l}\text { No; Referred for Special } \\
\text { Education Testing }\end{array}$ & No & None & $\mathrm{O}, \mathrm{S}$, and $\mathrm{X}$ \\
\hline
\end{tabular}

Note. PALS: Phonological Awareness and Literacy Screening

Table 2

Letters Identified Per Session For Cameron

\begin{tabular}{|c|c|c|c|c|c|c|c|c|c|c|}
\hline \multirow{2}{*}{$\begin{array}{c}\text { Targeted } \\
\text { Letters }\end{array}$} & \multicolumn{10}{|c|}{ Letters Identified Per Session } \\
\hline & 1 & 2 & 3 & 4 & 5 & 6 & 7 & 8 & 9 & 10 \\
\hline \multicolumn{11}{|c|}{ T1 - TeachTown Basics ${ }^{\mathrm{TM}}$} \\
\hline $\mathrm{D}$ & 0 & 1 & 1 & 1 & 3 & 1 & 0 & 0 & 1 & \\
\hline $\mathrm{T}$ & 1 & 0 & 1 & 2 & 3 & 0 & 2 & 0 & 1 & \\
\hline I & 4 & 2 & 3 & 1 & 2 & 1 & 2 & 2 & 5 & \\
\hline $\mathrm{H}$ & 3 & 3 & 5 & 3 & 4 & 5 & 5 & 5 & 5 & \\
\hline $\mathrm{R}$ & 2 & 3 & 2 & 2 & 3 & 0 & 4 & 4 & 5 & \\
\hline \multicolumn{11}{|c|}{$\mathrm{T} 2$ - Traditional Teaching } \\
\hline $\mathrm{U}$ & 0 & 0 & 0 & 1 & 1 & 1 & 0 & 2 & 1 & \\
\hline $\mathrm{N}$ & 2 & 0 & 1 & 0 & 1 & 2 & 0 & 1 & 1 & \\
\hline
\end{tabular}




$\begin{array}{llllllllll}\mathrm{J} & 1 & 0 & 1 & 1 & 0 & 3 & 1 & 1 & 1 \\ \mathrm{Y} & 1 & 1 & 0 & 2 & 0 & 1 & 1 & 1 & 2 \\ \mathrm{Q} & 1 & 3 & 2 & 1 & 1 & 3 & 1 & 0 & 2\end{array}$

Table 3

Letters Identified Per Session For Hannah

\begin{tabular}{|c|c|c|c|c|c|c|c|c|c|c|}
\hline \multirow{2}{*}{$\begin{array}{c}\text { Targeted } \\
\text { Letters }\end{array}$} & \multicolumn{10}{|c|}{ Letters Identified Per Session } \\
\hline & 1 & 2 & 3 & 4 & 5 & 6 & 7 & 8 & 9 & 10 \\
\hline \multicolumn{11}{|c|}{ T1 - TeachTown Basics ${ }^{\mathrm{TM}}$} \\
\hline $\mathrm{D}$ & 0 & 1 & 0 & 1 & 1 & -- & 0 & 0 & 0 & -- \\
\hline $\mathrm{T}$ & 1 & 1 & 0 & 0 & 0 & -- & 0 & 0 & 1 & -- \\
\hline $\mathrm{I}$ & 2 & 2 & 1 & 2 & 2 & -- & 2 & 1 & 0 & -- \\
\hline $\mathrm{H}$ & 0 & 1 & 0 & 2 & 1 & -- & 0 & 0 & 0 & -- \\
\hline $\mathrm{R}$ & 0 & 1 & 0 & 2 & 3 & -- & 0 & 0 & 1 & -- \\
\hline \multicolumn{11}{|c|}{$\mathrm{T} 2$ - Traditional Teaching } \\
\hline $\mathrm{U}$ & 0 & 0 & 0 & 1 & 0 & -- & 0 & 1 & 1 & -- \\
\hline $\mathrm{N}$ & 2 & 1 & 0 & 0 & 0 & -- & 1 & 0 & 1 & -- \\
\hline $\mathrm{J}$ & 1 & 0 & 0 & 1 & 2 & -- & 2 & 0 & 2 & -- \\
\hline $\mathrm{Y}$ & 2 & 1 & 0 & 0 & 0 & -- & 3 & 0 & 1 & -- \\
\hline Q & 2 & 1 & 0 & 1 & 0 & -- & 2 & 2 & 1 & -- \\
\hline
\end{tabular}

Table 4

Letters Identified Per Session For Kylie

\begin{tabular}{|c|c|c|c|c|c|c|c|c|c|c|}
\hline \multirow{2}{*}{$\begin{array}{c}\text { Targeted } \\
\text { Letters }\end{array}$} & \multicolumn{10}{|c|}{ Letters Identified Per Session } \\
\hline & 1 & 2 & 3 & 4 & 5 & 6 & 7 & 8 & 9 & 10 \\
\hline \multicolumn{11}{|c|}{ T1 - TeachTown Basics ${ }^{\mathrm{TM}}$} \\
\hline $\mathrm{D}$ & -- & 2 & -- & 3 & 0 & 1 & -- & 1 & -- & 2 \\
\hline $\mathrm{T}$ & -- & 0 & -- & 0 & 0 & 0 & -- & 1 & -- & 2 \\
\hline I & -- & 1 & -- & 0 & 0 & 2 & -- & 1 & -- & 1 \\
\hline $\mathrm{H}$ & -- & 0 & -- & 0 & 2 & 3 & -- & 0 & -- & 1 \\
\hline $\mathrm{R}$ & -- & 0 & -- & 2 & 1 & 1 & -- & 0 & -- & 5 \\
\hline
\end{tabular}


T2 - Traditional Teaching

$\begin{array}{ccccccccccc}\mathrm{U} & -- & 0 & -- & 1 & 1 & 0 & -- & 3 & -- & 0 \\ \mathrm{~N} & -- & 0 & -- & 0 & 1 & 1 & -- & 2 & -- & 2 \\ \mathrm{~J} & -- & 1 & -- & 1 & 2 & 2 & -- & 1 & -- & 1 \\ \mathrm{Y} & -- & 0 & -- & 0 & 2 & 1 & -- & 1 & -- & 2 \\ \mathrm{Q} & -- & 0 & -- & 0 & 1 & 2 & -- & 2 & -- & 0\end{array}$

Table 5

Letters Identified Per Session For Katie

\begin{tabular}{|c|c|c|c|c|c|c|c|c|c|c|}
\hline \multirow{2}{*}{$\begin{array}{c}\text { Targeted } \\
\text { Letters }\end{array}$} & \multicolumn{10}{|c|}{ Letters Identified Per Session } \\
\hline & 1 & 2 & 3 & 4 & 5 & 6 & 7 & 8 & 9 & 10 \\
\hline \multicolumn{11}{|c|}{ T1 - TeachTown Basics ${ }^{\mathrm{TM}}$} \\
\hline $\mathrm{D}$ & 1 & 1 & 1 & 1 & 1 & 1 & 1 & 2 & 0 & 2 \\
\hline $\mathrm{T}$ & 1 & 2 & 1 & 1 & 1 & 1 & 1 & 2 & 0 & 1 \\
\hline I & 1 & 2 & 1 & 0 & 1 & 0 & 1 & 0 & 0 & 1 \\
\hline $\mathrm{H}$ & 1 & 0 & 0 & 0 & 1 & 1 & 2 & 1 & 0 & 0 \\
\hline $\mathrm{R}$ & 2 & 1 & 2 & 2 & 0 & 1 & 3 & 1 & 1 & 0 \\
\hline \multicolumn{11}{|c|}{ T2 - Traditional Teaching } \\
\hline $\mathrm{U}$ & 0 & 1 & 2 & 0 & 1 & 0 & 2 & 1 & 0 & 0 \\
\hline $\mathrm{N}$ & 1 & 1 & 0 & 0 & 3 & 2 & 0 & 1 & 1 & 1 \\
\hline $\mathrm{J}$ & 4 & 0 & 0 & 1 & 2 & 0 & 1 & 1 & 0 & 0 \\
\hline Y & 2 & 2 & 1 & 2 & 1 & 1 & 3 & 0 & 2 & 1 \\
\hline $\mathrm{Q}$ & 2 & 1 & 0 & 3 & 0 & 2 & 1 & 1 & 2 & 0 \\
\hline
\end{tabular}

Table 6

Letters Identified Per Session For Serenity

\begin{tabular}{|c|c|c|c|c|c|c|c|c|c|c|}
\hline Targeted & \multicolumn{10}{|c|}{ Letters Identified Per Session } \\
\hline & 1 & 2 & 3 & 4 & 5 & 6 & 7 & 8 & 9 & 10 \\
\hline \multicolumn{11}{|c|}{$\mathrm{T} 1$ - TeachT1own Basics ${ }^{\mathrm{TM}}$} \\
\hline $\mathrm{D}$ & 0 & 1 & 1 & 2 & 2 & 1 & 1 & -- & 0 & 1 \\
\hline $\mathrm{T}$ & 1 & 0 & 0 & 0 & 1 & 1 & 1 & -- & 1 & 2 \\
\hline
\end{tabular}




$\begin{array}{lllllllllll}\mathrm{I} & 1 & 1 & 2 & 0 & 0 & 1 & 0 & -- & 2 & 1 \\ \mathrm{H} & 1 & 0 & 0 & 1 & 3 & 2 & 0 & -- & 2 & 0 \\ \mathrm{R} & 2 & 0 & 1 & 1 & 1 & 1 & 0 & -- & 2 & 0\end{array}$

T2 - Traditional Teaching

$\begin{array}{lllllllllll}\mathrm{U} & 1 & 0 & 0 & 1 & 1 & 2 & 3 & -- & 3 & 1 \\ \mathrm{~N} & 0 & 2 & 0 & 1 & 1 & 1 & 2 & -- & 1 & 0 \\ \mathrm{~J} & 0 & 1 & 1 & 0 & 1 & 1 & 1 & -- & 0 & 1 \\ \mathrm{Y} & 1 & 2 & 0 & 1 & 2 & 2 & 0 & -- & 0 & 1 \\ \mathrm{Q} & 1 & 1 & 0 & 1 & 0 & 1 & 0 & -- & 1 & 0\end{array}$

Table 7

Letters Identified Per Session For Sara

\begin{tabular}{|c|c|c|c|c|c|c|c|c|c|c|}
\hline \multirow{2}{*}{$\begin{array}{c}\text { Targeted } \\
\text { Letters }\end{array}$} & \multicolumn{10}{|c|}{ Letters Identified Per Session } \\
\hline & 1 & 2 & 3 & 4 & 5 & 6 & 7 & 8 & 9 & 10 \\
\hline \multicolumn{11}{|c|}{ T1 - TeachTown Basics ${ }^{\mathrm{TM}}$} \\
\hline $\mathrm{D}$ & 2 & 1 & 1 & -- & 0 & 1 & 1 & -- & -- & -- \\
\hline $\mathrm{T}$ & 1 & 1 & 1 & -- & 0 & 1 & 3 & -- & -- & -- \\
\hline $\mathrm{I}$ & 1 & 0 & 0 & -- & 1 & 1 & 2 & -- & -- & -- \\
\hline $\mathrm{H}$ & 5 & 5 & 4 & -- & 4 & 5 & 5 & -- & -- & -- \\
\hline $\mathrm{R}$ & 0 & 0 & 1 & -- & 0 & 2 & 2 & -- & -- & -- \\
\hline \multicolumn{11}{|c|}{$\mathrm{T} 2$ - Traditional Teaching } \\
\hline $\mathrm{U}$ & 1 & 0 & 0 & -- & 1 & 2 & 3 & -- & -- & -- \\
\hline $\mathrm{N}$ & 1 & 2 & 0 & -- & 1 & 1 & 2 & -- & -- & -- \\
\hline $\mathrm{J}$ & 1 & 1 & 1 & -- & 1 & 1 & 1 & -- & -- & -- \\
\hline $\mathrm{Y}$ & 0 & 2 & 0 & -- & 2 & 2 & 0 & -- & -- & -- \\
\hline Q & 1 & 1 & 0 & -- & 0 & 1 & 0 & -- & -- & -- \\
\hline
\end{tabular}


Table 8

Phonological Awareness and Literacy Screening (PALS) Results for Uppercase Alphabet Letter Recognition

\begin{tabular}{lcc}
\hline Participant & Quick Check & End of Year \\
\hline Cameron & 6 & 11 \\
Hannah & 0 & 1 \\
Kylie & 0 & 3 \\
Katie & 0 & 0 \\
Serenity & 0 & 0 \\
Sara & 3 & 7
\end{tabular}

Note. Spring developmental ranges for Uppercase Alphabet recognition are 12-21. The letters

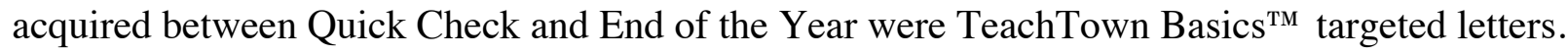


Figures

Figure 1

Mean Average Of Responses For Cameron

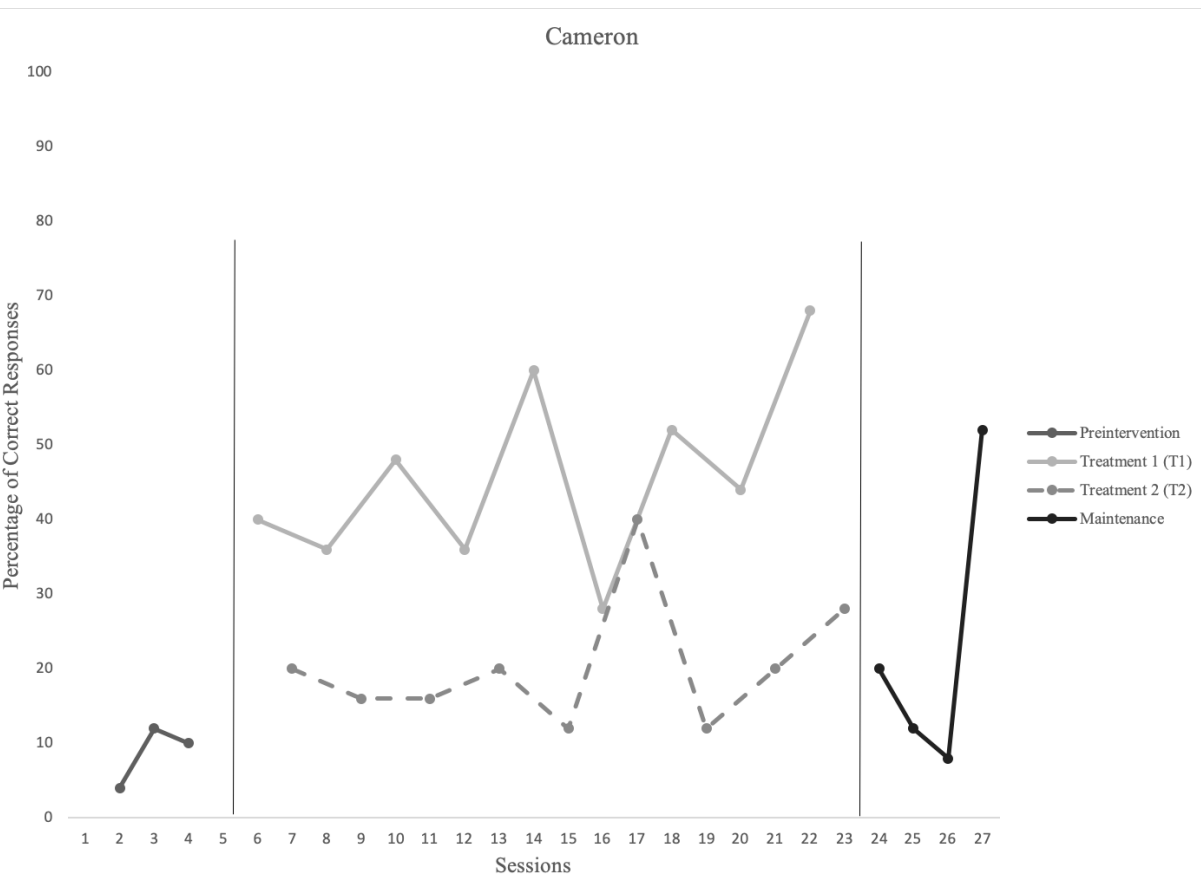


Figure 2

Mean Average Of Responses For Hannah

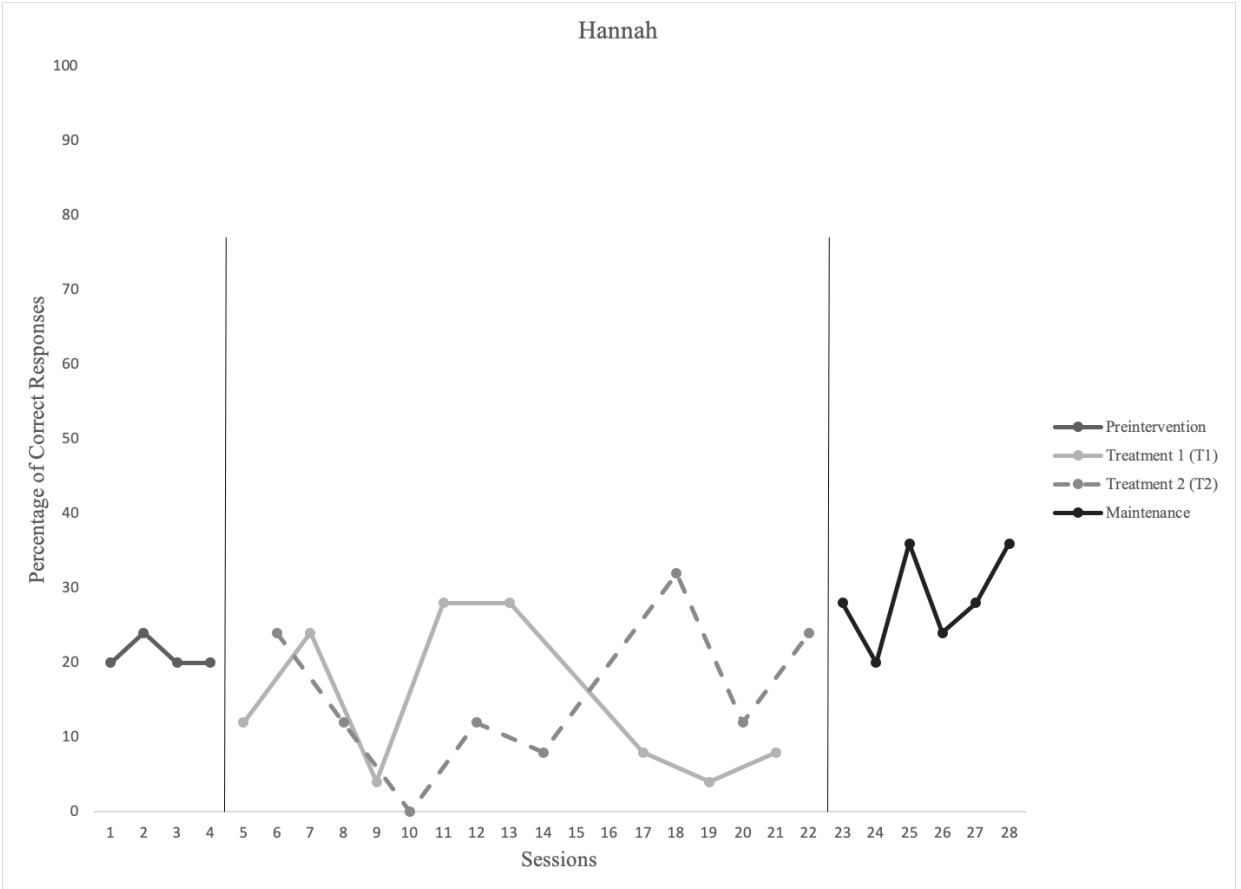

Figure 3

Mean Average Of Responses For Kylie

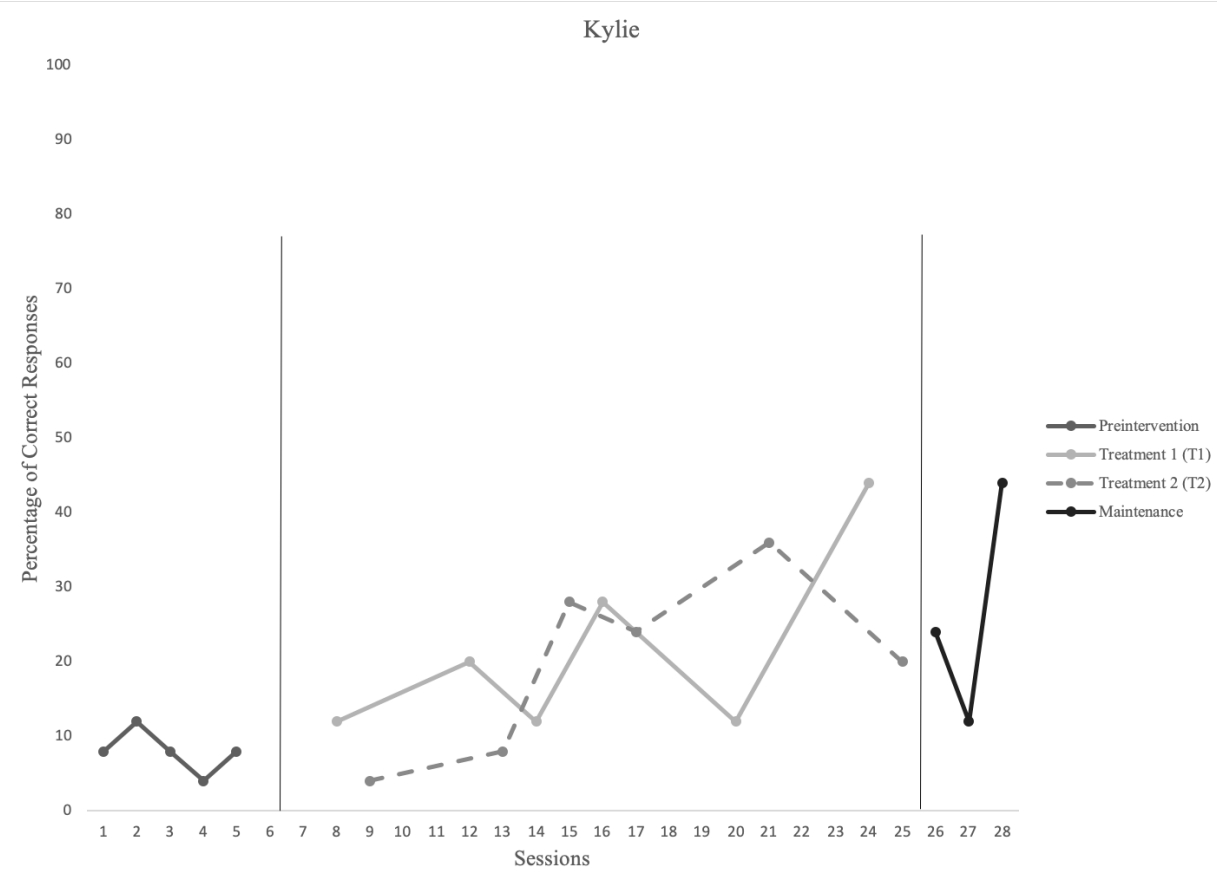


Figure 4

\section{Mean Average Of Responses For Katie}

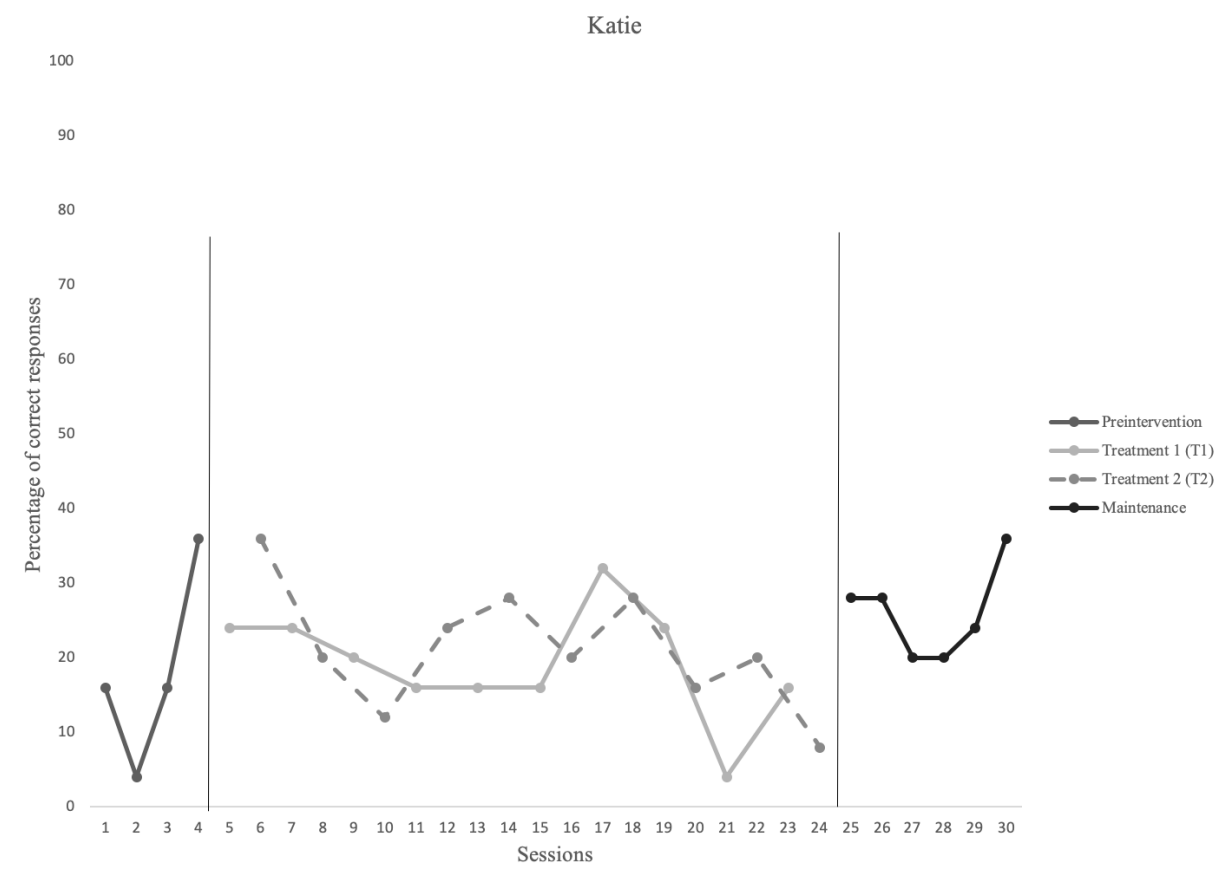

Figure 5

Mean Average Of Responses For Serenity

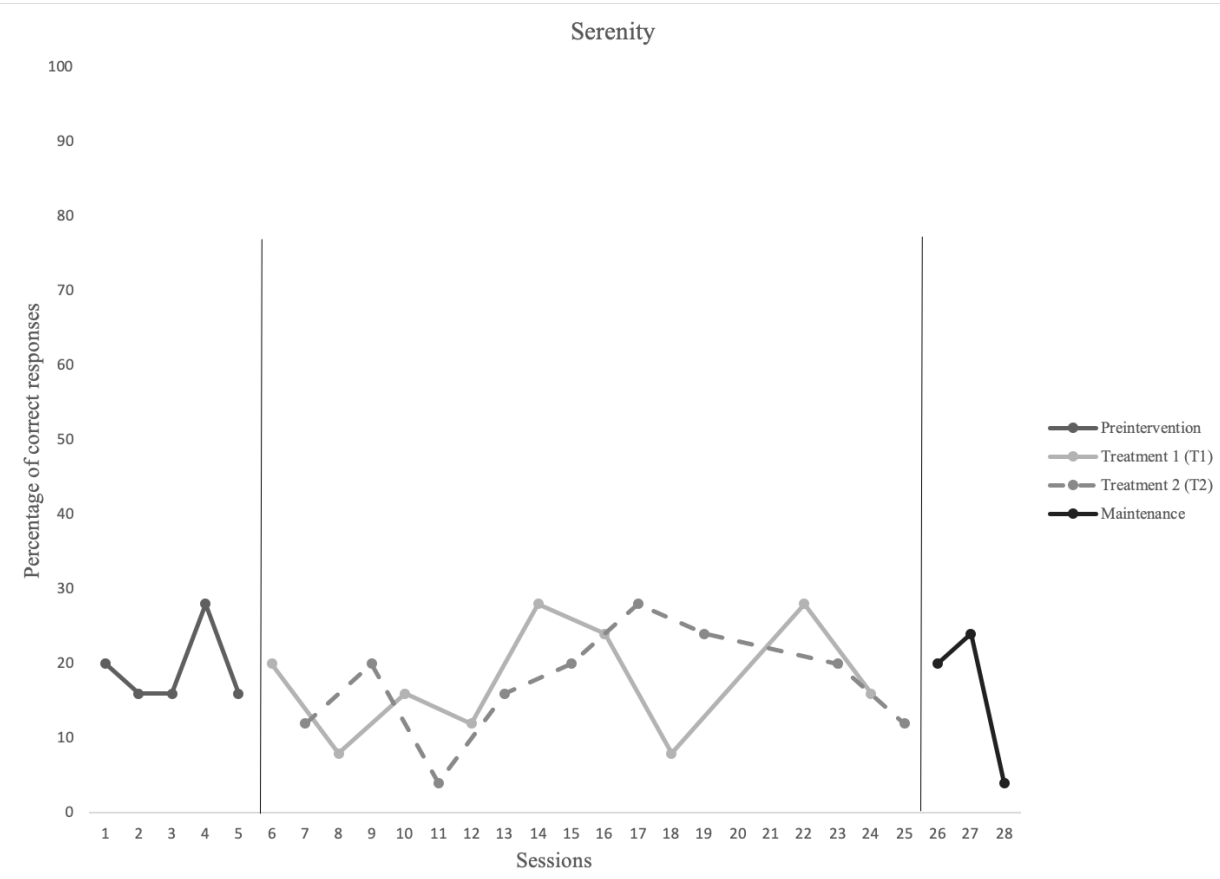


Figure 6

Mean Average Of Responses For Sara

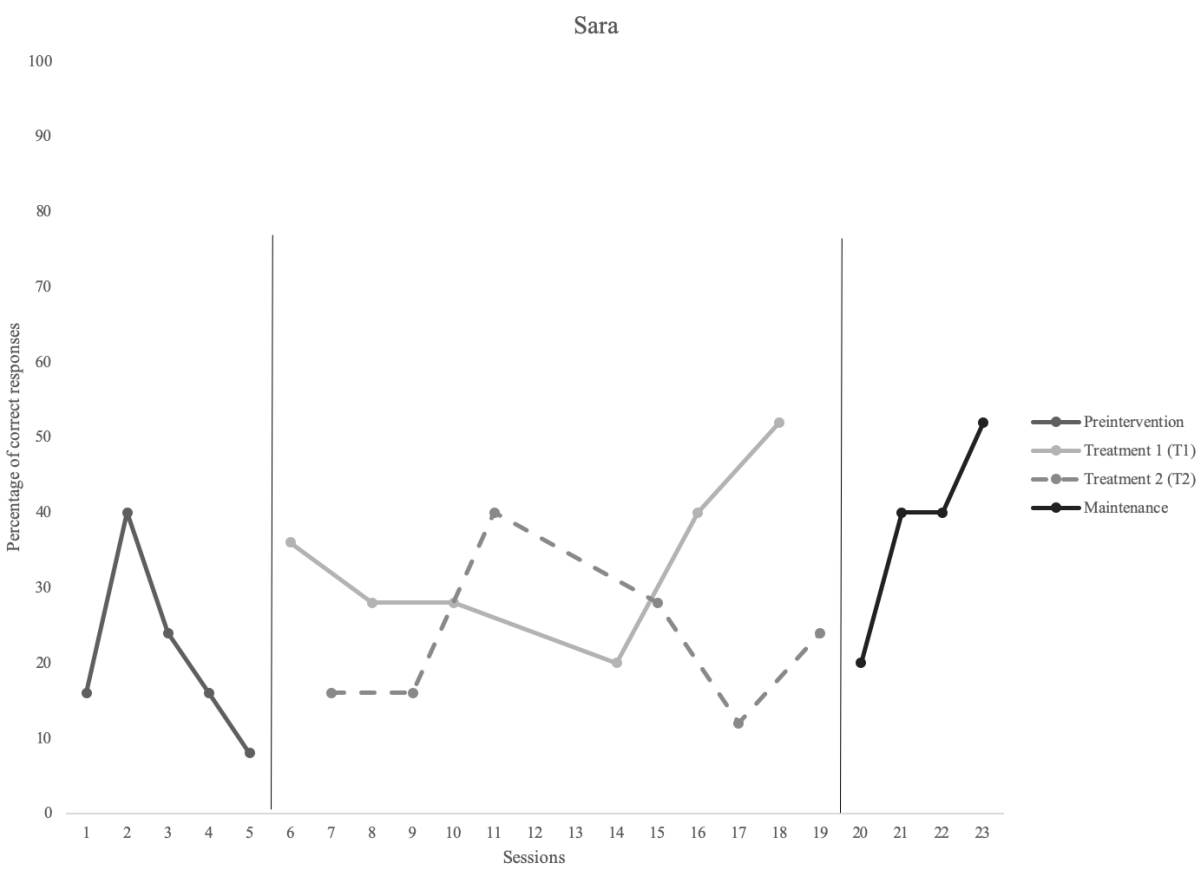


Appendix A

PALS Quick Check for Uppercase Letter Knowledge

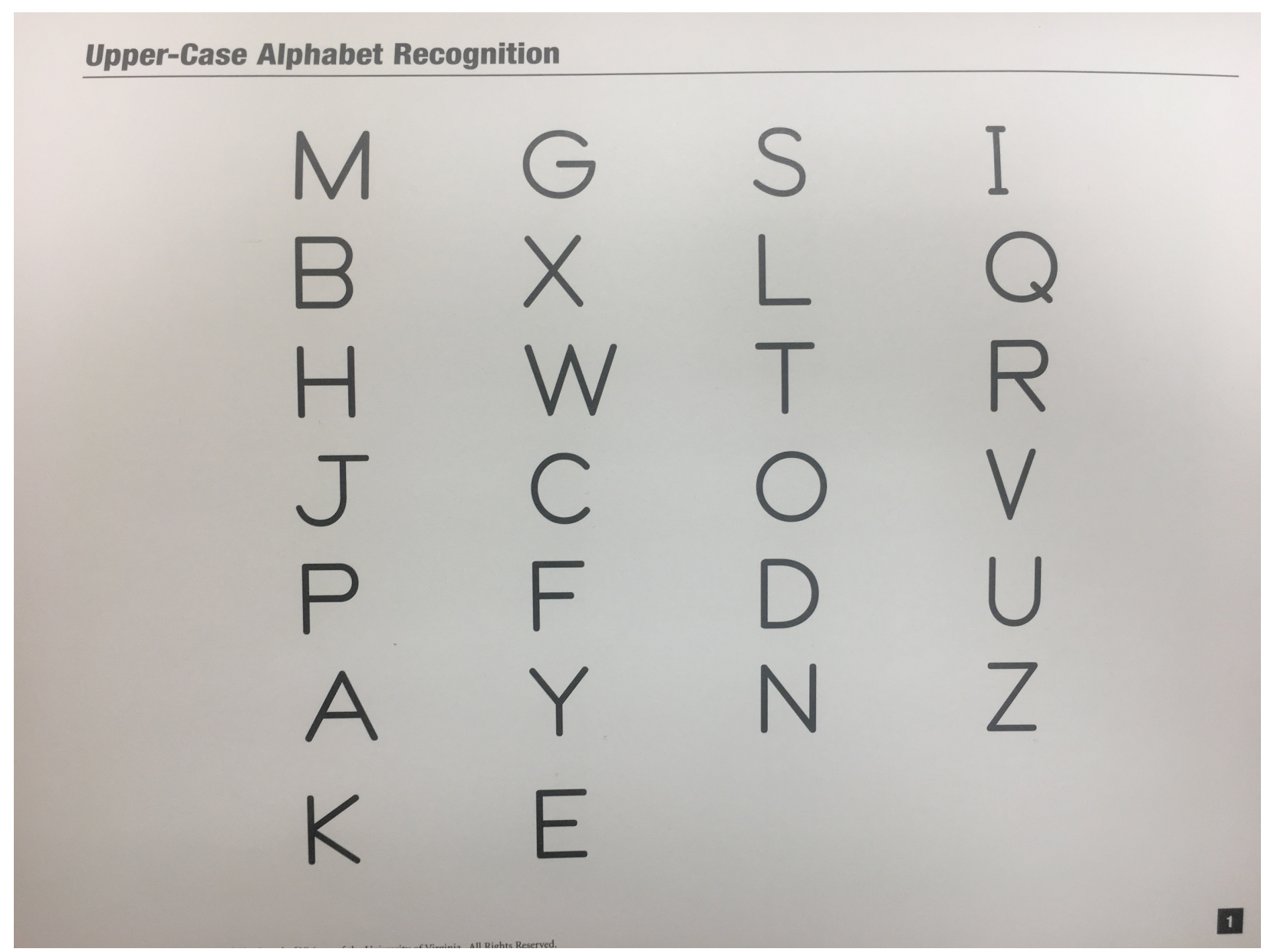




\section{Appendix B}

Samples of Materials for Interventions

Sample of Teacher Made Materials
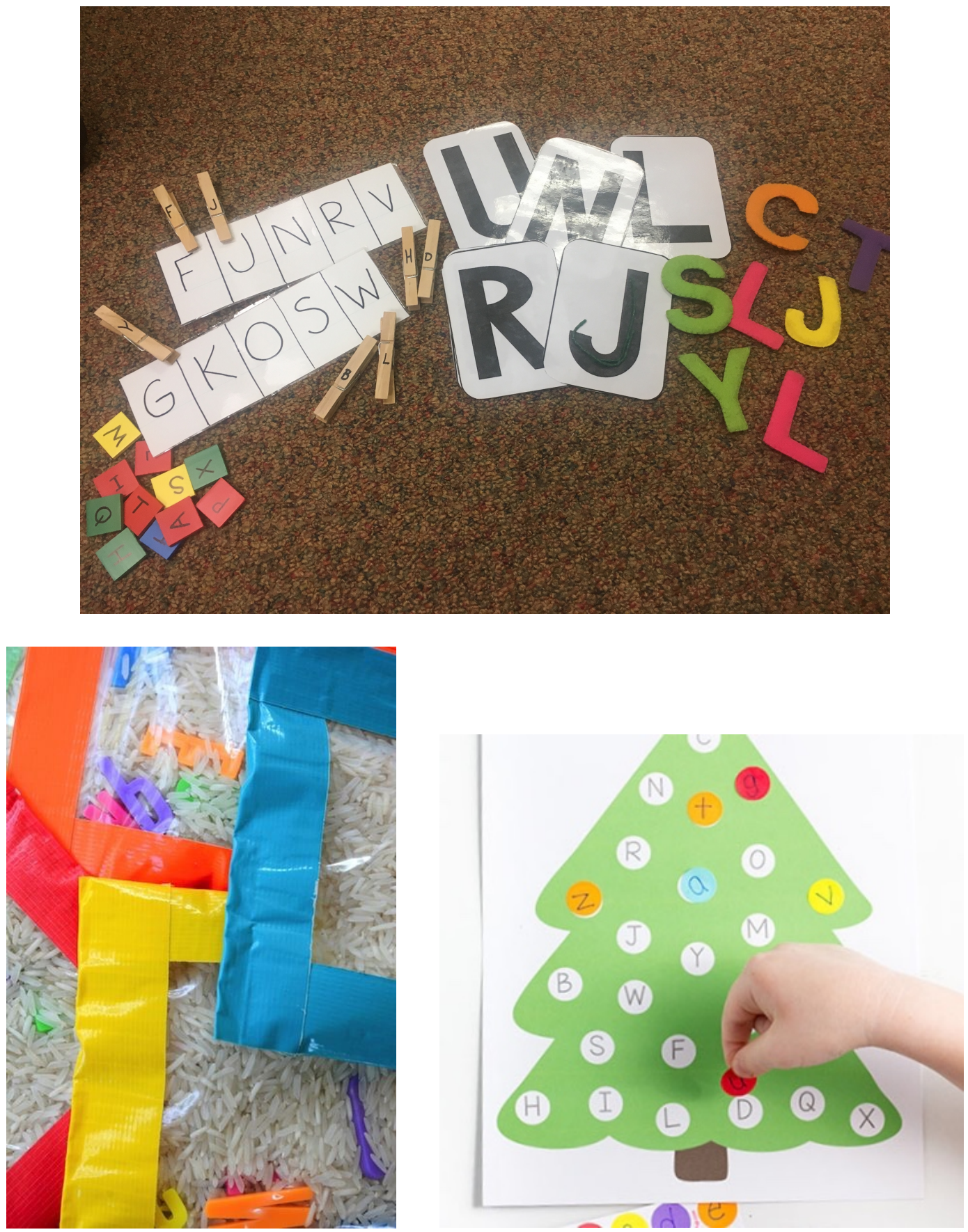
Sample of Purchased Materials
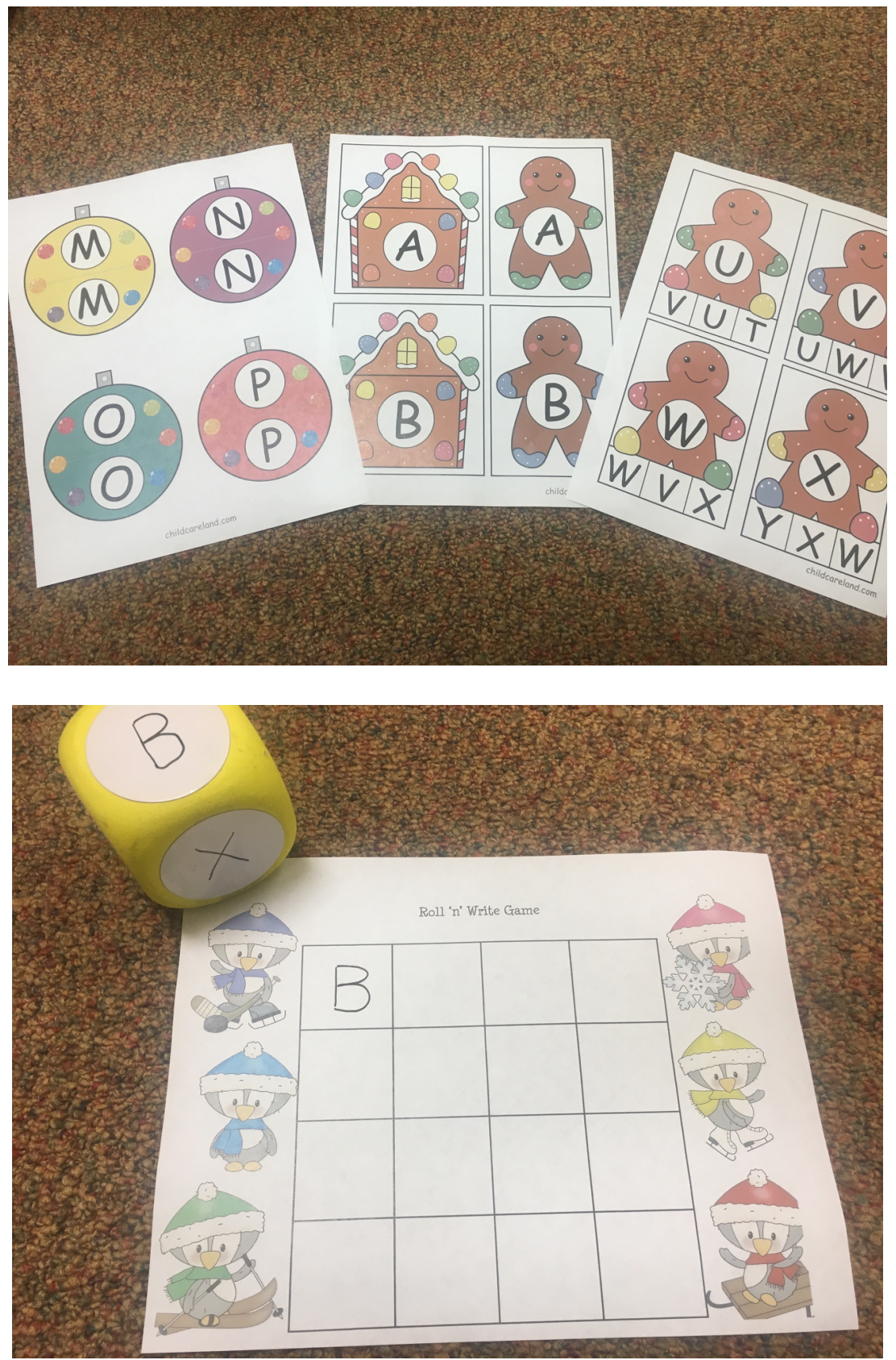

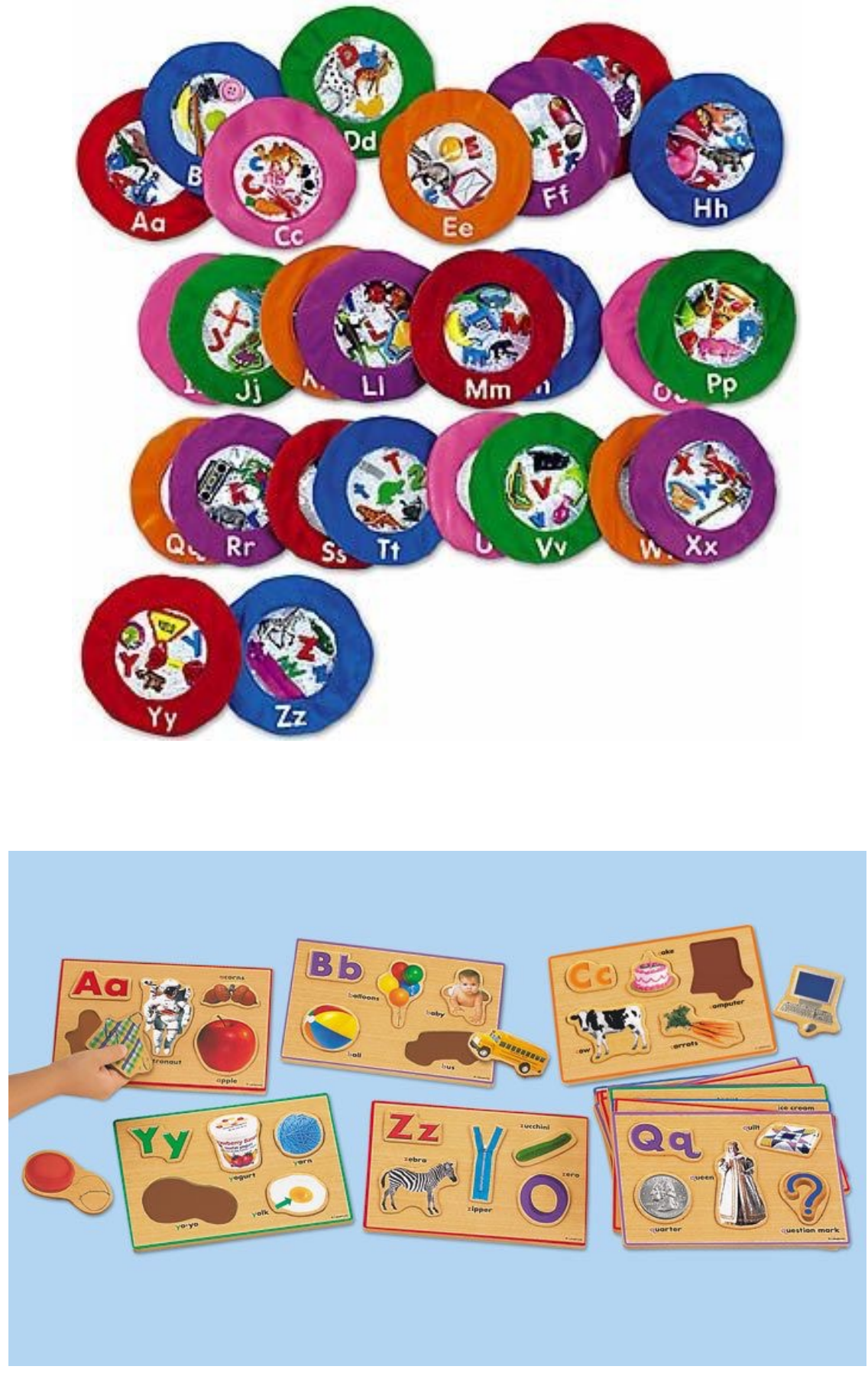

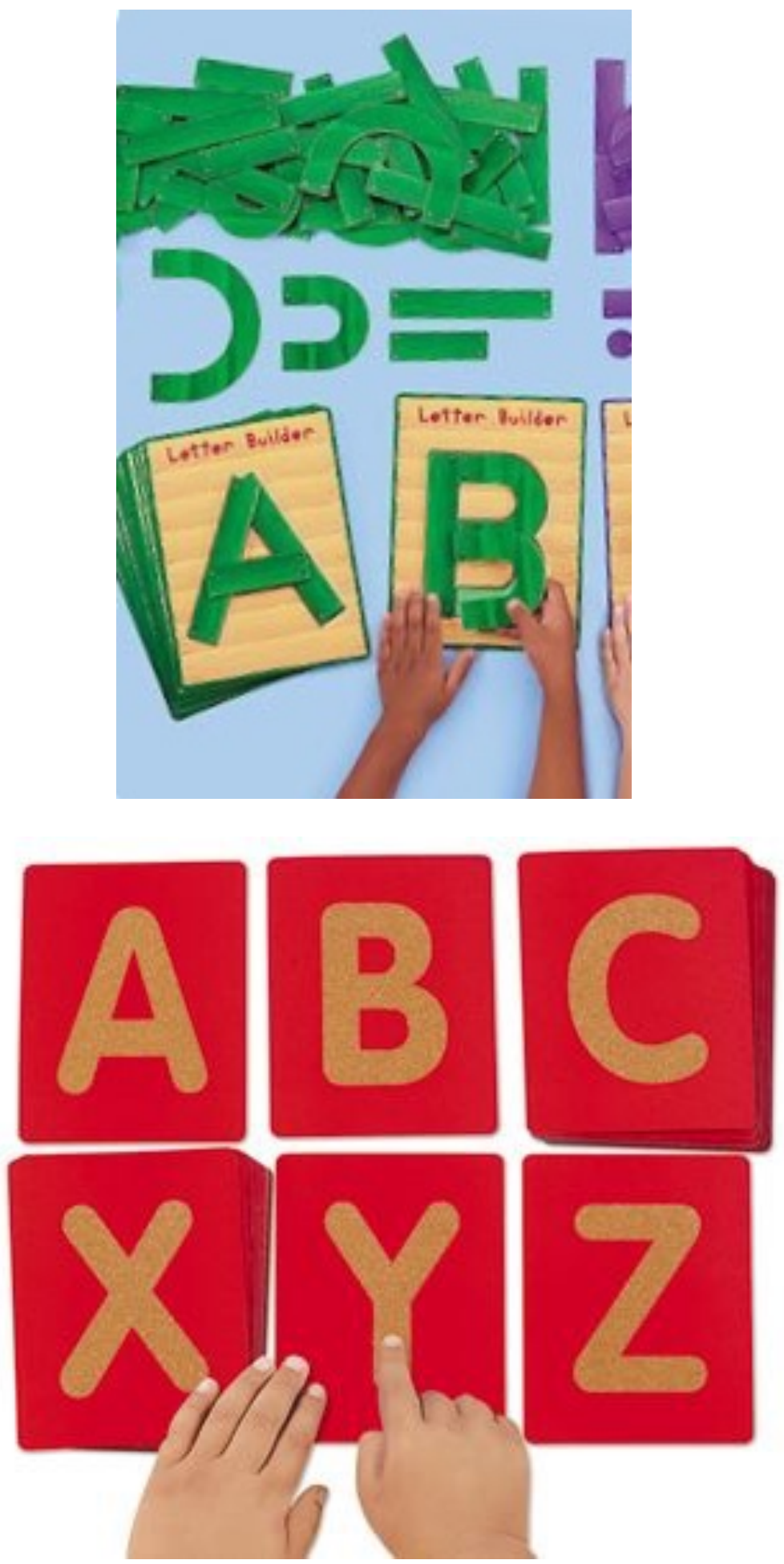

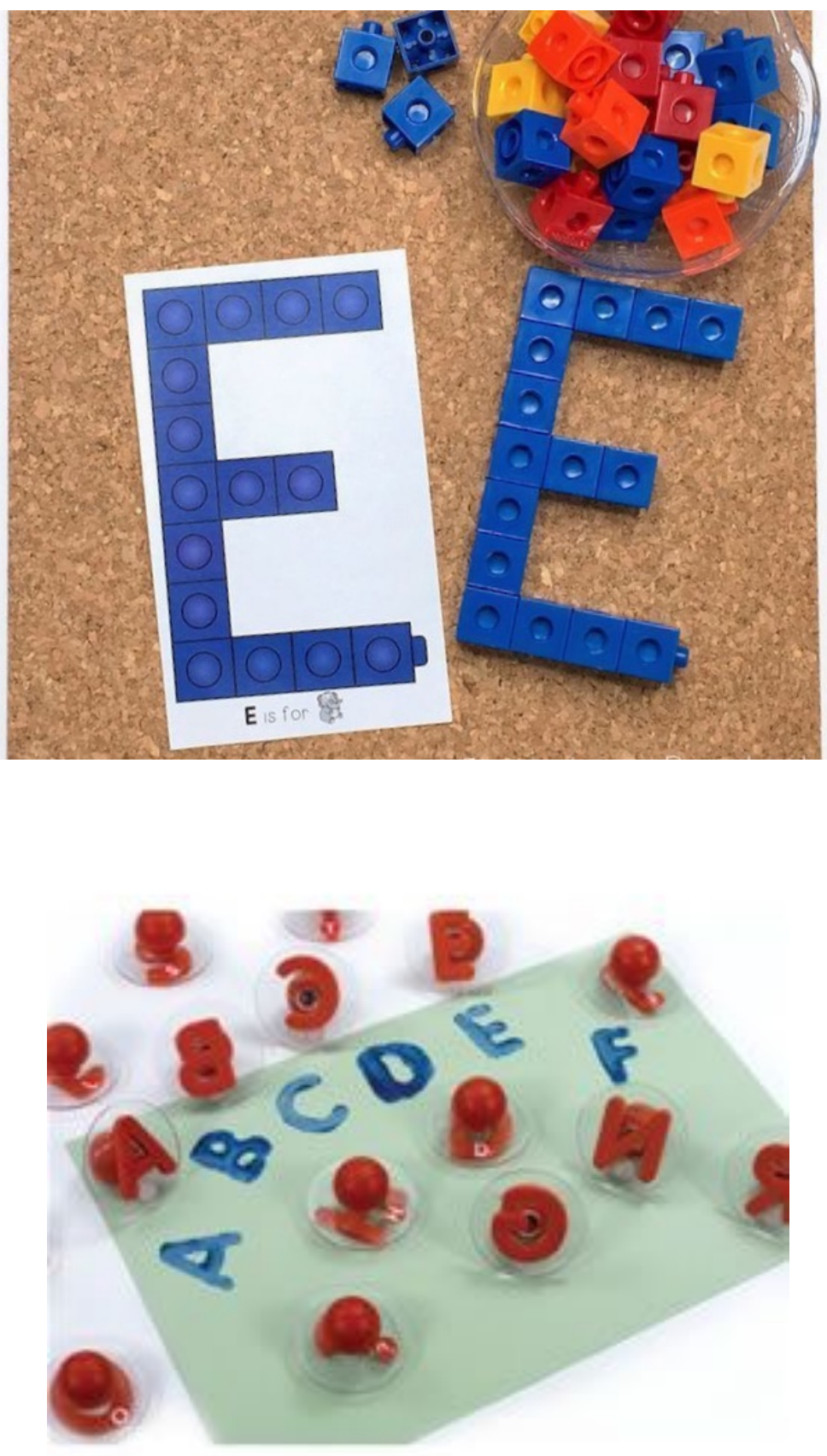


\section{Appendix C}

\section{Samples of Letter Groupings}

Individual Participant Letter Groupings

Preintervention 1

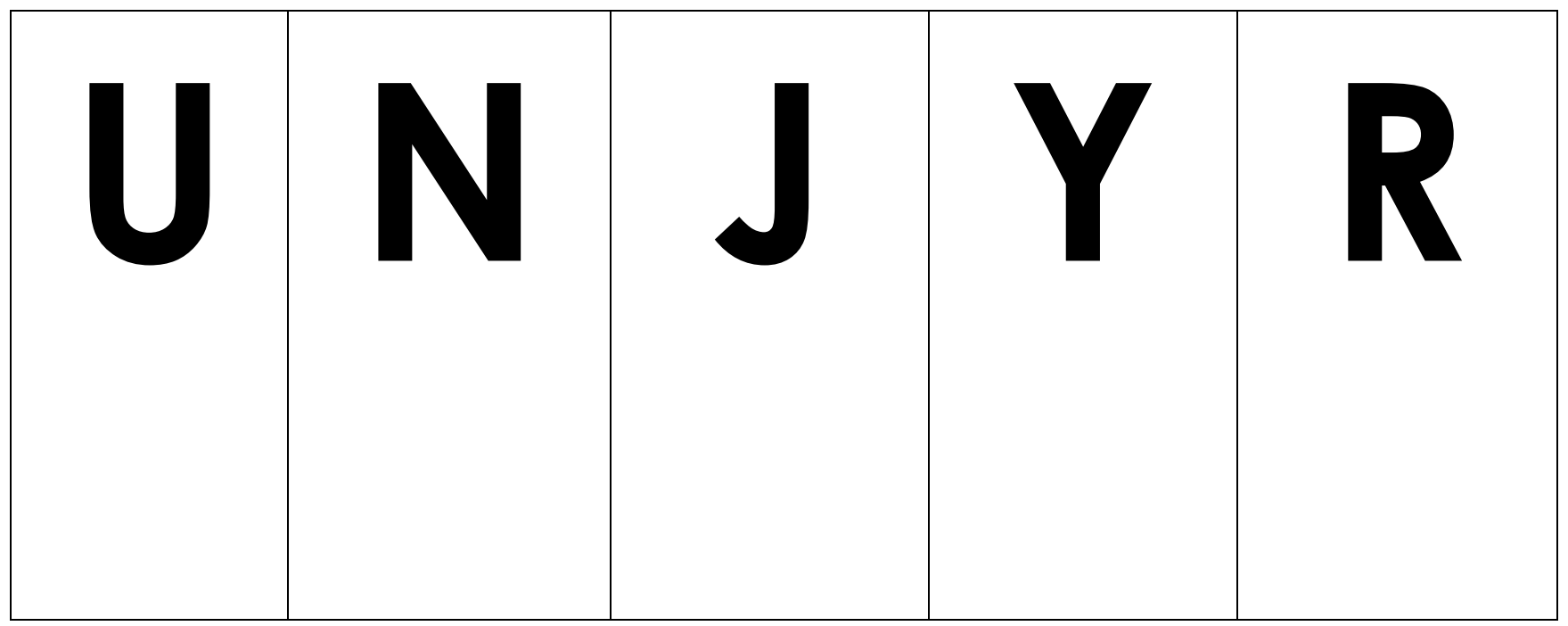

Preintervention 2

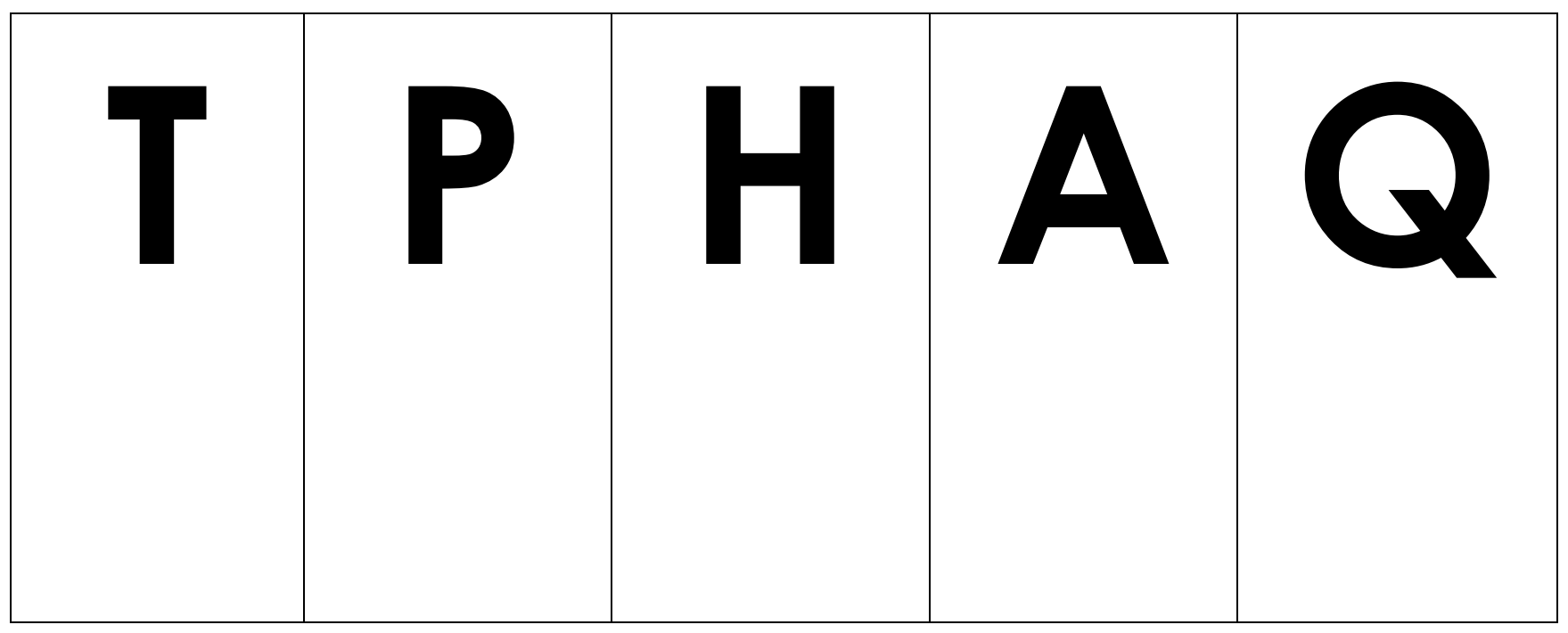


Preintervention 3

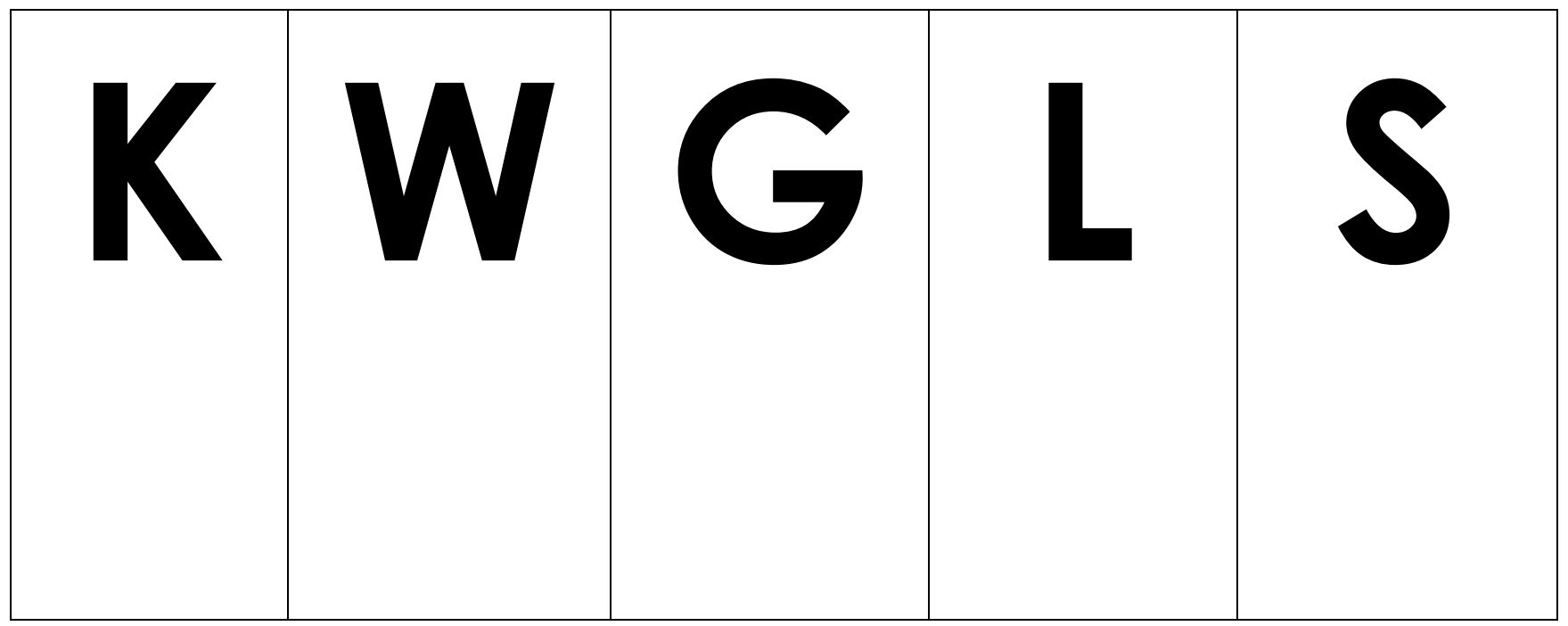

Preintervention 4

\begin{tabular}{|l|l|l|l|l|}
\hline & & & &
\end{tabular}


Preintervention 5

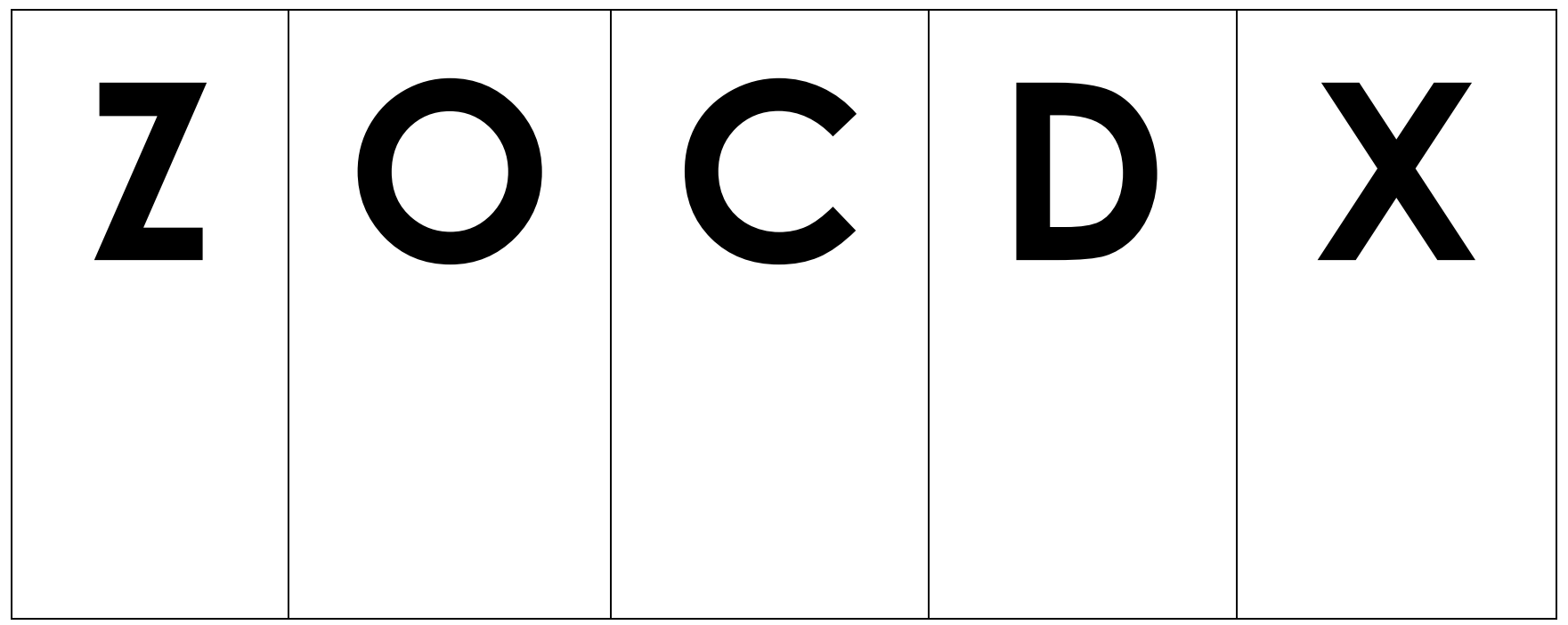

$\mathrm{T} 1$ Intervention

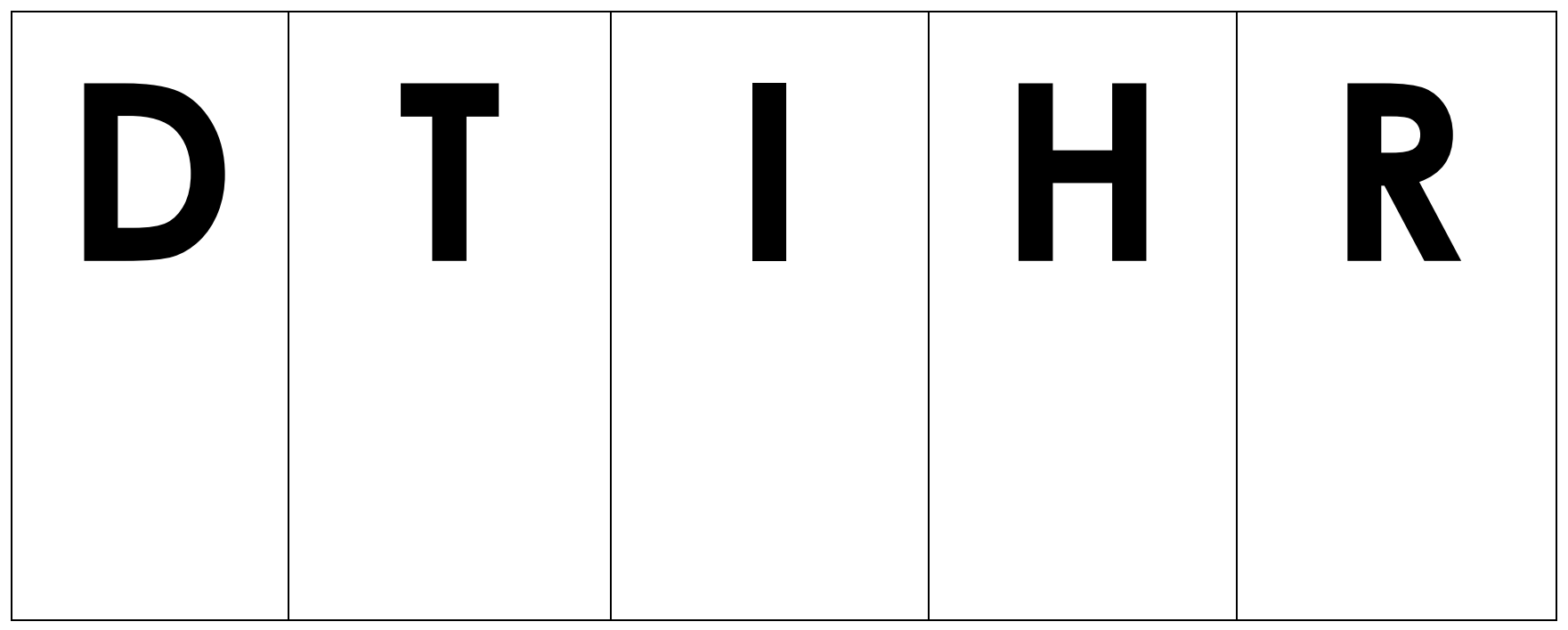


T2 Intervention

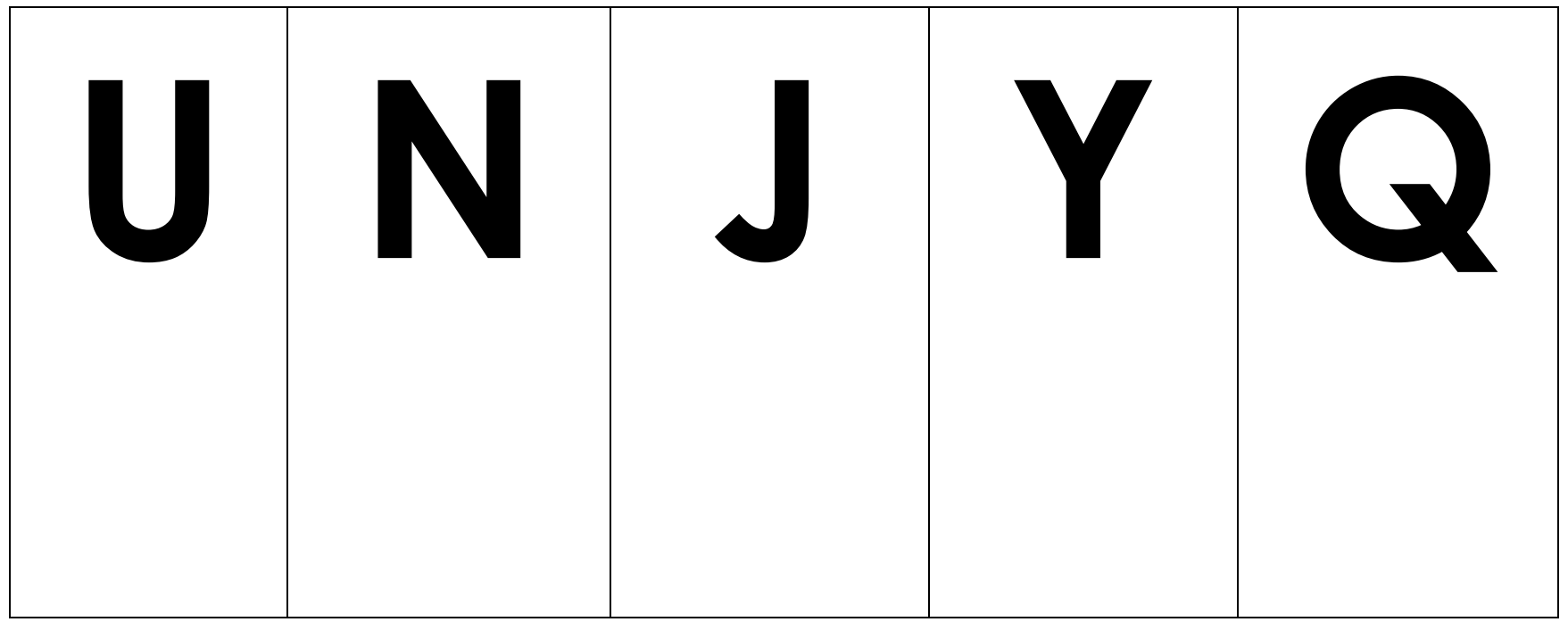

Maintenance

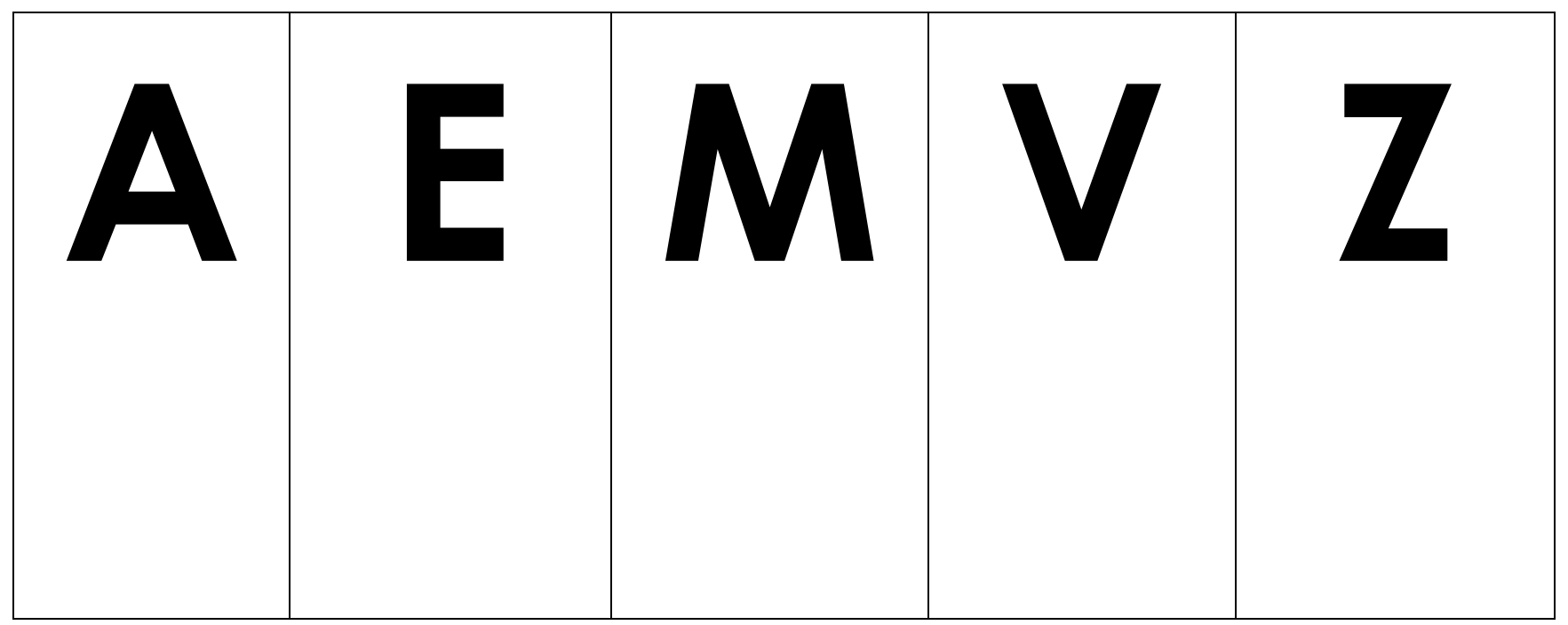




\section{Appendix D}

Sample of Probe Reporting Sheet

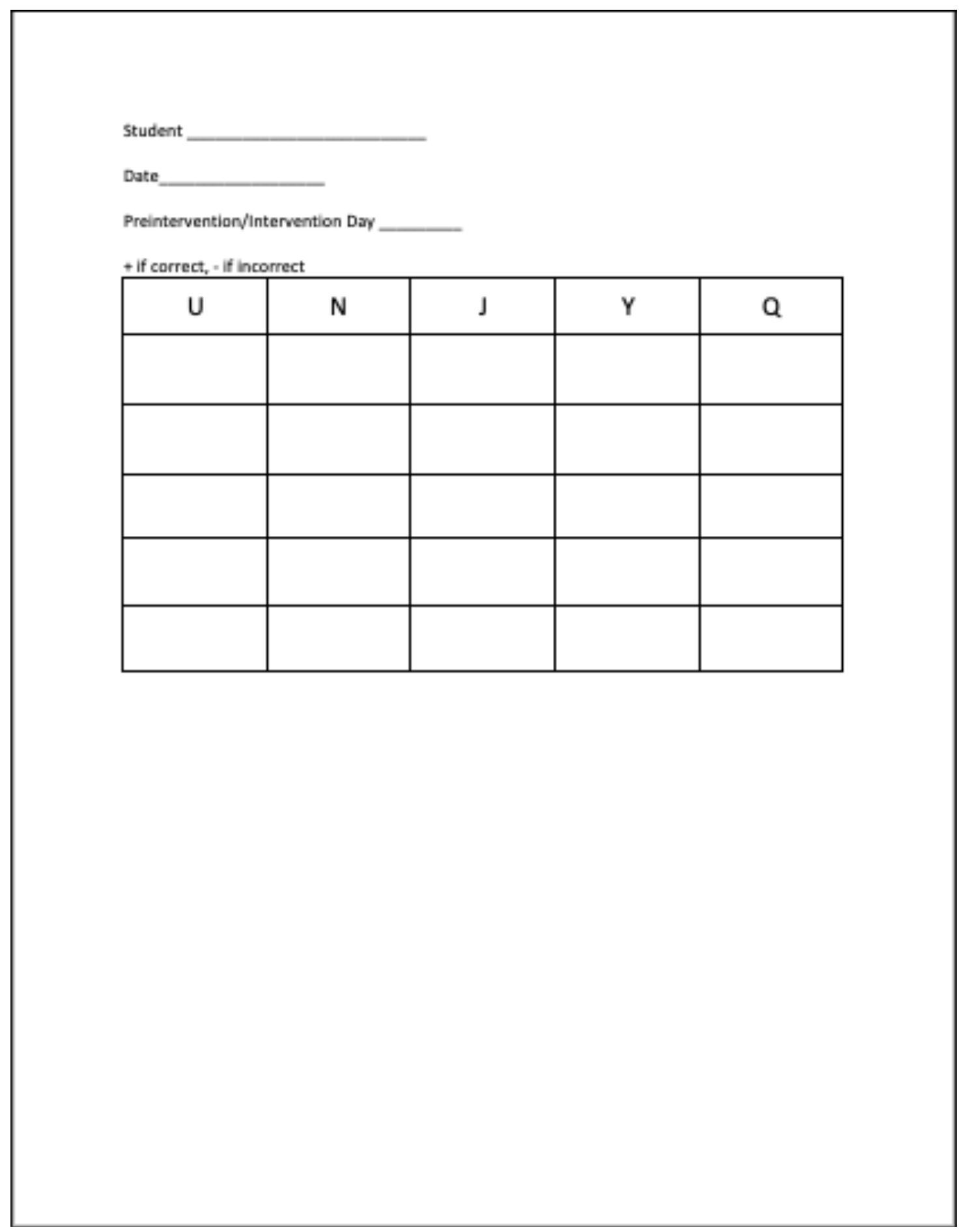




\section{Appendix E}

\section{Scripted Procedures for Preintervention}

Date:

\begin{tabular}{|l|l|}
\hline Task Completed & \\
\hline & Turn on video camera \\
\hline & $\begin{array}{l}\text { No letter intervention or activities are performed today, but centers are } \\
\text { open including activities that do not reflect alphabet letters and iPads } \\
\text { without letter recognition games. }\end{array}$ \\
\hline & $\begin{array}{l}\text { Say, “_ I would like for you to help me find some letters" to } \\
\text { each participant individually to initiate random probe. Ask the student, } \\
\text { "Show me the " in random order of the 5 letters selected. Do not } \\
\text { comment on correct or incorrect letters. Shuffle the cards and display } \\
\text { them again and repeat the process again for a total of 5 times }\end{array}$ \\
\hline & $\begin{array}{l}\text { Mark the probe with a to indicate correct identification and a - to } \\
\text { indicate an incorrect identification. }\end{array}$ \\
\hline $\begin{array}{l}\text { When complete, tell the child, "Thank you for helping me" and allow } \\
\text { them to choose an activity. }\end{array}$ \\
\hline Turn off video camera \\
\hline
\end{tabular}




\section{Appendix F}

Schedule of Treatments

\begin{tabular}{ccccccccccc}
\hline & & & \multicolumn{1}{c}{ Sessions } \\
\hline & 1 & 2 & 3 & 4 & 5 & 6 & 7 & 8 & 9 & 10 \\
\hline Cameron & $\mathrm{T} 2 / \mathrm{T} 1$ & $\mathrm{~T} 1 / \mathrm{T} 2$ & $\mathrm{~T} 2 / \mathrm{T} 1$ & $\mathrm{~T} 2 / \mathrm{T} 1$ & $\mathrm{~T} 2 / \mathrm{T} 1$ & $\mathrm{~T} 1 / \mathrm{T} 2$ & $\mathrm{~T} 2 / \mathrm{T} 1$ & $\mathrm{~T} 1 / \mathrm{T} 2$ & $\mathrm{~T} 1 / \mathrm{T} 2$ & $\mathrm{~T} 2 / \mathrm{T} 1$ \\
Hannah & $\mathrm{T} 2 / \mathrm{T} 1$ & $\mathrm{~T} 2 / \mathrm{T} 1$ & $\mathrm{~T} 1 / \mathrm{T} 2$ & $\mathrm{~T} 2 / \mathrm{T} 1$ & $\mathrm{~T} 2 / \mathrm{T} 1$ & $\mathrm{~T} 2 / \mathrm{T} 1$ & $\mathrm{~T} 1 / \mathrm{T} 2$ & $\mathrm{~T} 2 / \mathrm{T} 1$ & $\mathrm{~T} 2 / \mathrm{T} 1$ & $\mathrm{~T} 1 / \mathrm{T} 2$ \\
Kylie & $\mathrm{T} 1 / \mathrm{T} 2$ & $\mathrm{~T} 2 / \mathrm{T} 1$ & $\mathrm{~T} 2 / \mathrm{T} 1$ & $\mathrm{~T} 1 / \mathrm{T} 2$ & $\mathrm{~T} 1 / \mathrm{T} 2$ & $\mathrm{~T} 1 / \mathrm{T} 2$ & $\mathrm{~T} 2 / \mathrm{T} 1$ & $\mathrm{~T} 1 / \mathrm{T} 2$ & $\mathrm{~T} 1 / \mathrm{T} 2$ & $\mathrm{~T} 2 / \mathrm{T} 1$ \\
Katie & $\mathrm{T} 2 / \mathrm{T} 1$ & $\mathrm{~T} 1 / \mathrm{T} 2$ & $\mathrm{~T} 1 / \mathrm{T} 2$ & $\mathrm{~T} 1 / \mathrm{T} 2$ & $\mathrm{~T} 1 / \mathrm{T} 2$ & $\mathrm{~T} 2 / \mathrm{T} 1$ & $\mathrm{~T} 1 / \mathrm{T} 2$ & $\mathrm{~T} 1 / \mathrm{T} 2$ & $\mathrm{~T} 1 / \mathrm{T} 2$ & $\mathrm{~T} 2 / \mathrm{T} 1$ \\
Serenity & $\mathrm{T} 1 / \mathrm{T} 2$ & $\mathrm{~T} 1 / \mathrm{T} 2$ & $\mathrm{~T} 2 / \mathrm{T} 1$ & $\mathrm{~T} 1 / \mathrm{T} 2$ & $\mathrm{~T} 1 / \mathrm{T} 2$ & $\mathrm{~T} 2 / \mathrm{T} 1$ & $\mathrm{~T} 2 / \mathrm{T} 1$ & $\mathrm{~T} 2 / \mathrm{T} 1$ & $\mathrm{~T} 2 / \mathrm{T} 1$ & $\mathrm{~T} 1 / \mathrm{T} 2$ \\
Sara & $\mathrm{T} 1 / \mathrm{T} 2$ & $\mathrm{~T} 2 / \mathrm{T} 1$ & $\mathrm{~T} 1 / \mathrm{T} 2$ & $\mathrm{~T} 2 / \mathrm{T} 1$ & $\mathrm{~T} 2 / \mathrm{T} 1$ & $\mathrm{~T} 1 / \mathrm{T} 2$ & $\mathrm{~T} 1 / \mathrm{T} 2$ & $\mathrm{~T} 2 / \mathrm{T} 1$ & $\mathrm{~T} 2 / \mathrm{T} 1$ & $\mathrm{~T} 1 / \mathrm{T} 2$
\end{tabular}

Note. Treatments are listed in the order in which they were to be administered for the particular day. Absences are not noted on the chart. 


\section{Appendix G}

Scripted Procedures for CAI Intervention (T1)

Date:

\begin{tabular}{|l|l|}
\hline Task Completed & \\
\hline & Turn on video camera \\
\hline & $\begin{array}{l}\text { Insure iPads are charged and logged in to Teach Town Basics } \\
\text { the home page of the program. Make sure each iPad has the correct } \\
\text { headphones and sound is working. }\end{array}$ \\
\hline & $\begin{array}{l}\text { Confirm no other letter intervention or activities are performed today } \\
\text { table with the iPad. Complete this with all children in the group. Tell the } \\
\text { children that they will work until the timer goes off. }\end{array}$ \\
\hline $\begin{array}{l}\text { Set timer for 10 minutes and allow the child to complete the tasks } \\
\text { independently while the teacher or assistant teacher sits with the group. } \\
\text { No questions can be answered, unless it is related to a technical issue. } \\
\text { Document any issues below. }\end{array}$ \\
\hline $\begin{array}{l}\text { When time is up, take each child individually and say, " } \\
\text { would like for you to help me find some letters" to each participant } \\
\text { individually to initiate random probe. Ask the student, "Show me the }\end{array}$ \\
$\begin{array}{l}\text { correct or incorrect letters. Shuffle the cards and ask again for a total of 5 } \\
\text { times. }\end{array}$ \\
$\begin{array}{l}\text { Mark the probe with a to indicate correct identification and a - to } \\
\text { indicate an incorrect identification. }\end{array}$ \\
$\begin{array}{l}\text { When complete, tell the child, "Thank you for helping me" and allow } \\
\text { them to choose an activity until it is time to switch to the other } \\
\text { intervention. }\end{array}$ \\
Turn off video camera when all interventions are complete. \\
\hline
\end{tabular}




\section{Appendix $\mathrm{H}$}

Scripted Procedures for Traditional Intervention (T2)

Date:

\begin{tabular}{|l|l|}
\hline Task Completed & \\
\hline & Turn on video camera \\
\hline & Insure all materials are arranged and easily accessible at the table. \\
\hline & $\begin{array}{l}\text { Sayfirm no other letter intervention or activities are performed today } \\
\text { children to the table with the materials. Tell the children that they will } \\
\text { work until the timer goes off. }\end{array}$ \\
\hline $\begin{array}{l}\text { Each session will consist of materials that would be typically supported in } \\
\text { the classroom during center time. Activities must include matching letter } \\
\text { uppercase to uppercase and other Creative Curriculum } \\
\text { activities approved letter }\end{array}$ \\
\hline $\begin{array}{l}\text { Set timer for 10 minutes and allow the child to complete the tasks while } \\
\text { the teacher or assistant teacher sits with the group. The teacher or } \\
\text { assistant teacher may identify letters for students and answer questions } \\
\text { about the letters as they would typically do during center activities. If a } \\
\text { student moves to another center, document what the child did in the other } \\
\text { center. Document any issues below. }\end{array}$ \\
\hline $\begin{array}{l}\text { When time is up, take each child individually and say, " } \\
\text { would like for you to help me find some letters" to each participant } \\
\text { individually to initiate random probes. Ask the student, "Show me the }\end{array}$ \\
$\begin{array}{l}\text { correct or incorrect letters. Shuffle the cards and repeat the process for a } \\
\text { total of 5 probes }\end{array}$ \\
$\begin{array}{l}\text { Mark the probe with a to indicate correct identification and a - to } \\
\text { indicate an incorrect identification. }\end{array}$ \\
$\begin{array}{l}\text { When complete, tell the child, "Thank you for helping me" and allow } \\
\text { them to choose an activity. }\end{array}$ \\
\hline Turn off video camera when all interventions have concluded for the day. \\
\hline
\end{tabular}




\section{Appendix I}

\section{Sample of Teacher and Assistant Teacher Survey}

TeachTown Basics Teacher and Assistant Teacher Survey

\begin{tabular}{|c|c|c|c|c|c|c|}
\hline & $\begin{array}{l}\text { Strongly } \\
\text { Disagree }\end{array}$ & Disagree & $\begin{array}{l}\text { Slightly } \\
\text { Disagree }\end{array}$ & $\begin{array}{c}\text { Slightly } \\
\text { Agree }\end{array}$ & Agree & $\begin{array}{c}\text { Strongly } \\
\text { Agree }\end{array}$ \\
\hline 1. & & & & & & \\
\hline $\begin{array}{l}\text { 2. I feel that the use of TeachTown improved } \\
\text { the alphabet letter recognition for my } \\
\text { students }\end{array}$ & & & & & & \\
\hline $\begin{array}{l}\text { 3. Other teachers would benefit from the use } \\
\text { of TeachTown }\end{array}$ & & & & & & \\
\hline $\begin{array}{l}\text { 4. I would recommend TeachTown to other } \\
\text { early childhood educators. }\end{array}$ & & & & & & \\
\hline $\begin{array}{l}\text { 5. The children who were targeted during the } \\
\text { study had deficits in early literacy skills. }\end{array}$ & & & & & & \\
\hline $\begin{array}{l}\text { 6. I would use TeachTown again to target } \\
\text { early literacy skills. }\end{array}$ & & & & & & \\
\hline $\begin{array}{l}\text { 7. I would be interested in using the entire } \\
\text { TeachTown program to target other } \\
\text { developmental skills }\end{array}$ & & & & & & \\
\hline $\begin{array}{l}\text { 8. I feel that TeachTown would be beneficial } \\
\text { for all students in my class. }\end{array}$ & & & & & & \\
\hline $\begin{array}{l}\text { 9. I have found other methods of teaching } \\
\text { early literacy skills to students with IEPs } \\
\text { more effective. }\end{array}$ & & & & & & \\
\hline $\begin{array}{l}\text { 10. I have used other computer-assisted } \\
\text { instruction in the past. }\end{array}$ & & & & & & \\
\hline $\begin{array}{l}\text { 11. I found TeachTown easy to implement in } \\
\text { my classroom. }\end{array}$ & & & & & & \\
\hline $\begin{array}{l}\text { 12. I found the use of technology to teach early } \\
\text { literacy motivating. }\end{array}$ & & & & & & \\
\hline $\begin{array}{l}\text { 13.I liked the lesson format used in } \\
\text { TeachTown. }\end{array}$ & & & & & & \\
\hline $\begin{array}{l}\text { 14. Overall, I am happy with my experiences } \\
\text { with using TeachTown. }\end{array}$ & & & & & & \\
\hline
\end{tabular}

\section{Comments}


Appendix $\mathbf{J}$

Student Work Samples

Hannah

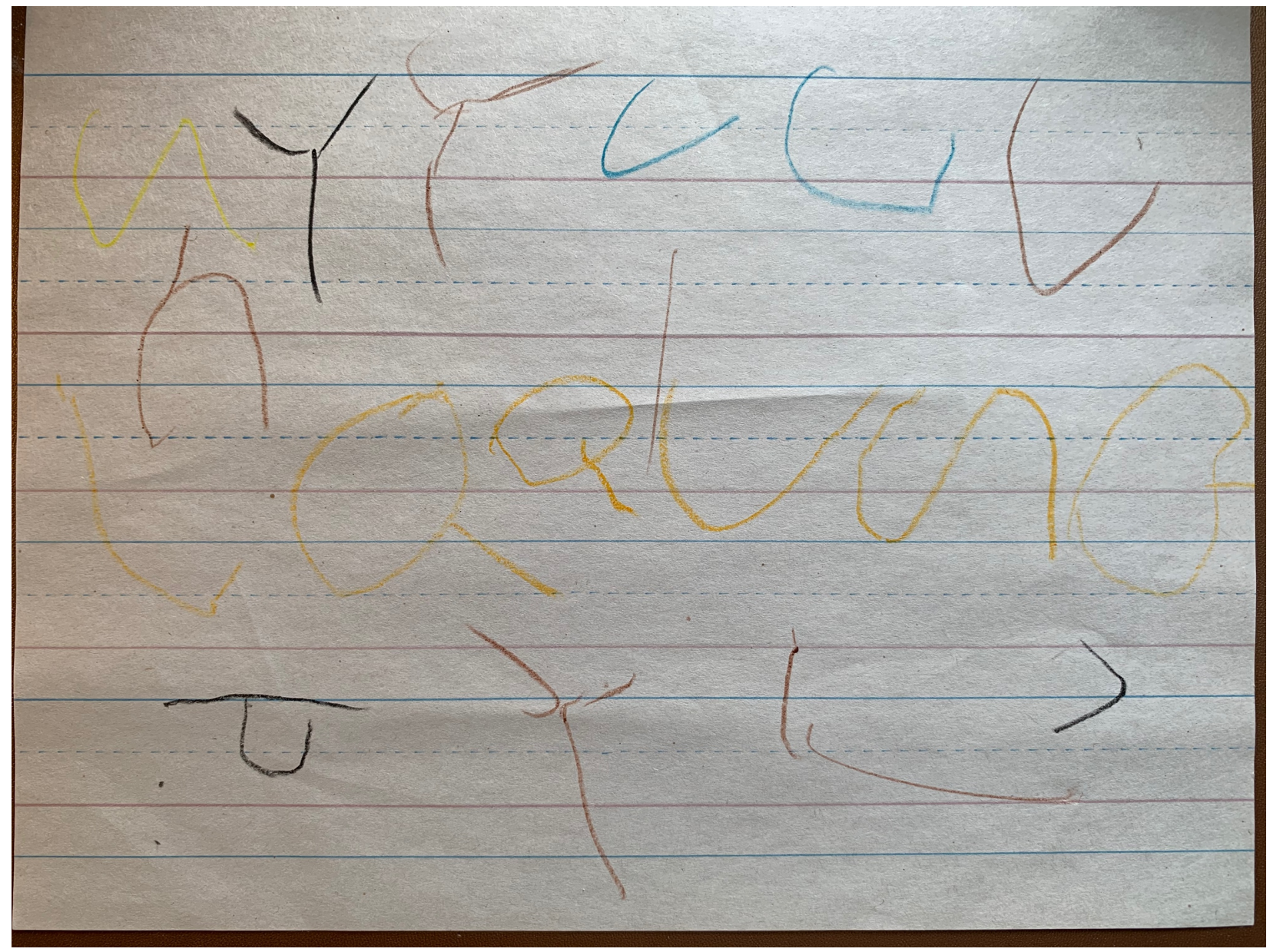


Serenity

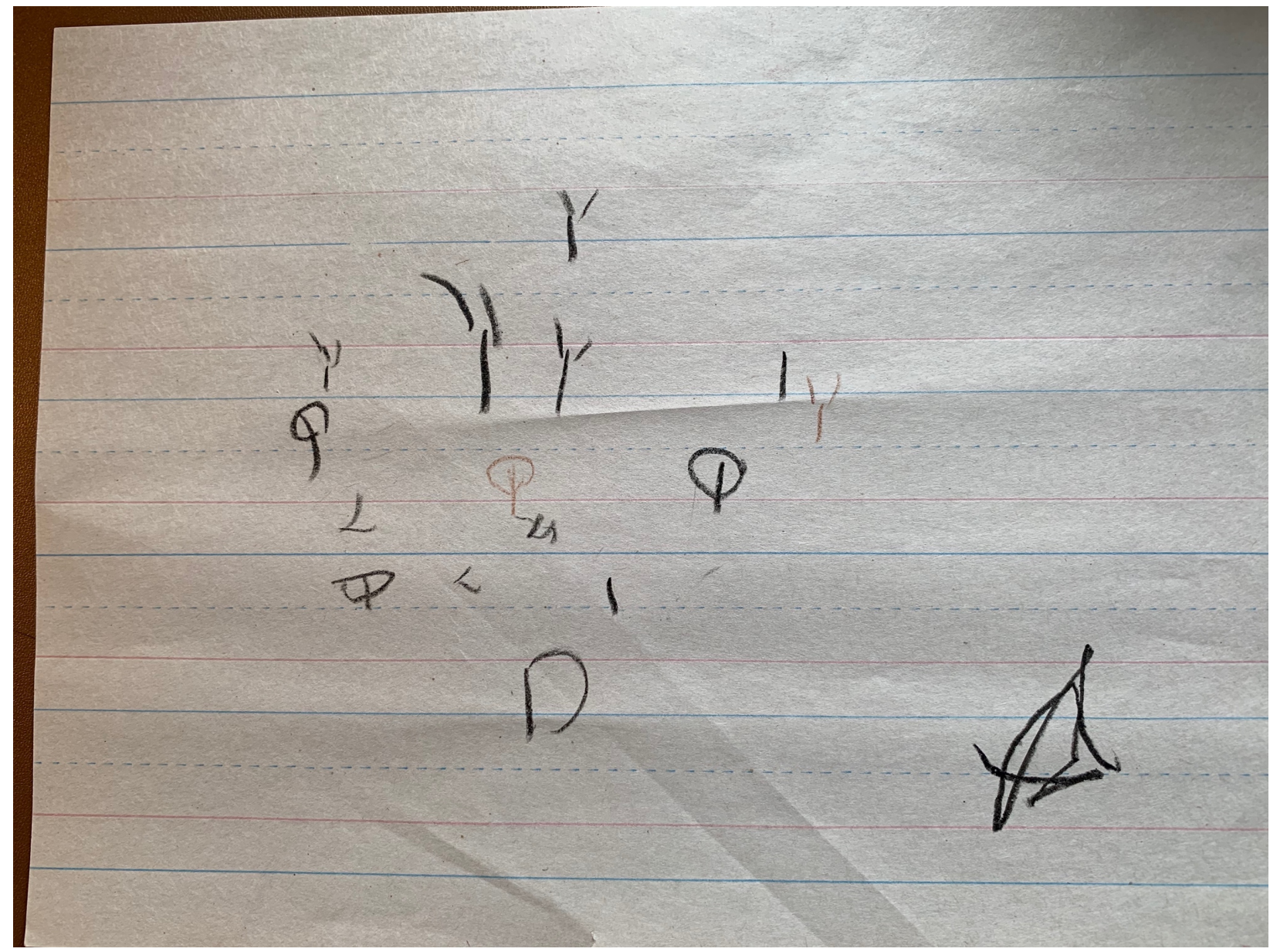

